\title{
THE
}

\section{Global Observations of Quasi-Zonal Bands in Microwave Sea Surface Temperature}

\author{
C. E. Buckingham \\ P. C. Cornillon \\ University of Rhode Island, pcornillon@uri.edu \\ F. Schloesser \\ K. M. Obenour
}

Follow this and additional works at: https://digitalcommons.uri.edu/gsofacpubs

Terms of Use

All rights reserved under copyright.

\section{Citation/Publisher Attribution}

Buckingham, C. E., P. C. Cornillon, F. Schloesser, and K. M. Obenour (2014), Global observations of quasizonal bands in microwave sea surface temperature, J. Geophys. Res. Oceans, 119, 4840-4866, doi: 10.1002/2014JC010088.

Available at: http://dx.doi.org/10.1002/2014JC010088

This Article is brought to you for free and open access by the Graduate School of Oceanography at DigitalCommons@URI. It has been accepted for inclusion in Graduate School of Oceanography Faculty Publications by an authorized administrator of DigitalCommons@URI. For more information, please contact digitalcommons-group@uri.edu. 


\title{
Journal of Geophysical Research: Oceans
}

\section{RESEARCH ARTICLE Global observations of quasi-zonal bands in microwave sea 10.1002/2014JC010088 surface temperature}

Key Points:

- Multiple quasi-zonal bands are observed in microwave sea surface temperature

- Bands in short-duration averages result from neighboring eddies of opposite sign

- Mild-to-strong persistence is observed in most of the world ocean

Correspondence to:

C. E. Buckingham,

c.e.buckingham@soton.ac.uk

Citation:

Buckingham, C. E., P. C. Cornillon, F. Schloesser, and K. M. Obenour (2014), Global observations of quasizonal bands in microwave sea surface temperature, J. Geophys. Res. Oceans, 119, 4840-4866, doi:10.1002 2014JC010088.

\author{
C. E. Buckingham 1, P. C. Cornillon², F. Schloesser², and K. M. Obenour² \\ ${ }^{1}$ National Oceanography Centre, University of Southampton, Southampton, UK, ${ }^{2}$ Graduate School of Oceanography, \\ University of Rhode Island, Narragansett, Rhode Island, USA
}

\begin{abstract}
Global observations of quasi-zonal jet-like structures have recently been reported in estimates of upper ocean circulation. To date, these observations have come primarily from float-derived and altimeter-derived estimates of zonal velocity. Here, we explore the existence of similar structures in the ocean using satellite-derived estimates of sea surface temperature (SST) from the Advanced Microwave Scanning Radiometer for the Earth Observing System (AMSR-E). Applying an ocean front detection algorithm globally to microwave measurements of SST, we find that repeated ocean fronts occur along quasizonal bands in a multiyear (2002-2011) average of detections. Such a pattern is also observed in SST gradient magnitude. Composite analyses of SST, sea surface height (SSH), and upper ocean temperatures from Argo profiling floats suggest repeated fronts in the subtropics occur as a result of neighboring anticyclonic and cyclonic eddies. Horizontal advection in the presence of a background temperature gradient likely plays a role as evidenced by the tilt of temperature anomalies with depth. High gradient events found within the bands are observed to propagate westward with speed comparable to mesoscale eddies and we estimate these events explain $20 \%$ of the observed variance in SST gradient magnitude (2002-2011). In a final analysis, we regress the decay of the bands with averaging period and observe mild-to-strong persistence throughout much of the World Ocean. These findings support the view that propagating eddies help give rise to the bands. Whether or not eddies follow preferred paths remain unanswered.
\end{abstract}

\section{Introduction}

Significant progress has been made in recent years with regard to our understanding of ocean circulation, particularly at the mesoscale. Here we define mesoscale currents as consisting of signals which vary over periods $>15 \mathrm{~d}$ and distances of 50-400 km. (While a strict definition of the mesoscale would include scales down to $30 \mathrm{~km}$ [Wunsch and Stammer, 1998], we define the lower limit of the mesoscale as $50 \mathrm{~km}$ since within this study we make use of a microwave radiometer-based data set and an optimally interpolated altimeter-based data set, both of which are capable of resolving only features with scales near $50 \mathrm{~km}$ [Chelton and Wentz, 2005; Chelton et al., 2011a].) While other technical advancements have undoubtably contributed to this understanding, three technical and methodological achievements have contributed significantly: the merger and optimal interpolation of sea surface height (SSH) measurements made by satellite altimeters [Ducet et al., 2000; Le Traon et al., 2003], development of a mesoscale-resolution mean dynamic topography (MDT) estimate [e.g., Maximenko et al., 2009; Rio et al., 2011] and development and systematic deployment of vertically profiling floats in the upper ocean [Roemmich et al., 2001]. These data sets are reviewed in detail in section 2 .

\subsection{Observations of Multiple Zonal Jet-Like Structures in the Oceans}

As a result of these advances, scientists have reported the existence of mesoscale multiple zonal jets in the World Ocean. Referred to as quasi-zonal in reference to their departure from a strictly zonal orientation and latent owing to their $O\left(1 \mathrm{~cm} \mathrm{~s}^{-1}\right)$ magnitude relative to the more dominant $O\left(10 \mathrm{~cm} \mathrm{~s}^{-1}\right)$ eddy field, these jet-like structures have been observed globally [Maximenko et al., 2005, 2008] and regionally in studies involving each or a combination of the aforementioned data sets (altimeter SSH, MDT, and Argo). Regional studies include those in the subtropics [Huang et al., 2007; Centurioni et al., 2008; Scott et al., 2008; Ivanov et al., 2009, 2010; van Sebille et al., 2011; Buckingham and Cornillon, 2013], Southern Ocean [Sokolov and Rintoul, 2007] and near-equatorial waters [Cravatte et al., 2012; Qiu et al., 2013]. Some suggestion of their existence is also found within the trajectories of Lagrangian isopycnal floats in the Deep Brazil Basin [Hogg and 
Owens, 1999] and in ocean reanalysis of the Indian Ocean [Divakaran and Brassington, 2011]. The currents alternate in direction and are nominally separated by $200 \mathrm{~km}$ [Maximenko et al., 2008].

\subsection{Several Interpretations of the Jet-Like Structures}

Despite their widespread appearance in oceanographic measurements, interpretations of the jet-like structures remain varied. The most common explanation given for the observed structures finds its roots in geostrophic turbulence theory [Charney, 1971; Rhines, 1975]. According to this theory, oceanic eddies interact in such a way that energy is transferred from small to large scales. In contrast, enstrophy cascades to increasingly smaller scales. The combined effects of the latitudinal variation in the Coriolis parameter and the inverse (forward) cascade of energy (enstrophy) are expected to result in multiple zonal jets [Rhines, 1975; Galperin et al., 2004]. A related theory which extends geostrophic turbulence to include long-range effects (i.e., "radiation stresses") of waves has also been proposed [Baldwin et al., 2007] and results in potential vorticity (PV) staircases [Dritschel and McIntyre, 2008].

A more recent explanation for the jet-like structures is given by Berloff et al. [2009] and relies upon primary and secondary instability mechanisms [Pedlosky, 1975]. Under this framework, energy from the background flow is transferred to instability modes characterized by large meridional and small zonal scales. These modes subsequently undergo a secondary instability that sets the meridional scale of the upper ocean and results in multiple zonal jets [Berloff et al., 2009, 2011]. An important aspect of this theory is the relationship between eddies and jets, whereby jets are maintained by the eddies [Kamenkovich et al., 2009; Berloff and Kamenkovich, 2013a, 2013b]. Additional explanations given for the observed structures include stochastic wind forcing [O'Reilly et al., 2012], radiating instabilities of an eastern boundary current [Hristova et al., 2008; Wang et al., 2012], $\beta$-plumes extending from the eastern boundary [Centurioni et al., 2008; Melnichenko et al., 2010; Afanasyev et al., 2012; Di Lorenzo et al., 2012] and the westward propagation of nonlinear mesoscale eddies [Schlax and Chelton, 2008; Scott et al., 2008; Marshall et al., 2013]. What is relevant for the present study is a distinction between eddies and jets.

One of the reasons for the diverse number of interpretations pertains to the definitions of an eddy and a jet. Within an oceanographic context, the former is easy to define: a mesoscale eddy is a closed circulation cell. (By this definition, we mean both nonlinear coherent vortices which trap fluid within their interior and Rossby waves whose flow at any given point in time can be described by closed, geostrophic streamlines.) A jet is more challenging to define. All of the aforementioned observational studies make use of timeaveraged oceanographic measurements in order to observe the structures. In particular, the averaging period is generally on the order of years. Those studies documenting the existence of jets therefore implicitly define a jet as an elongated current observed in the time-averaged velocity field. While valid in some respects, it fails to differentiate between two distinct oceanographic phenomena: localized, elongated, energetic flows [Rhines, 1994], and a tendency of PV anomalies of the same sign to propagate along similar paths [Scott et al., 2008]. Note that the time scale associated with the evolution/propagation of a mesoscale $\mathrm{PV}$ anomaly is close to $L / c=(100 \mathrm{~km}) /\left(2 \mathrm{~km} \mathrm{~d}^{-1}\right)=50 \mathrm{~d}$, where $L$ is a radius and $c$ a propagation speed typical of propagating mesoscale eddies [Chelton et al., 2011a]. To avoid confusion, we use the term jet in this paper to describe the first of these phenomena and preferred eddy paths to describe the latter. We understand this distinction is not entirely appropriate. Indeed, we find it is quite difficult to separate eddies and jets in Berloff and Kamenkovich [2013a, Figure 1b]. More formally, one would say that the decomposition of the observed velocity field into eddies and jets is not orthogonal owing to the nonzero correlation between the two phenomena. Nevertheless, we feel it is helpful for the present dialog and make this distinction, here.

A second reason for the diversity of interpretations is the finite nature of the observational record and limited conclusions that can be drawn from it. Schlax and Chelton [2008] develop a model of westwardpropagating eddies with random position and demonstrate that zonal geostrophic velocity when averaged in time, $\bar{u}$, contains jet-like structures. The implication is that observed multiple zonal jet-like structures could simply be an artifact of averaging a finite number of eddies in time. And although not included in such a model, a related mechanism is the trapping of fluid by westward-propagating nonlinear vortices [Robinson, 1983; Chelton et al., 2011a; Cushman-Roisin et al., 1990] and the associated return flow-i.e., Rossby rip currents [Marshall et al., 2013]. Buckingham and Cornillon [2013] pursued this line-of-thought further and found that a large fraction of the observed jet-like signal in $\bar{u}$ can explicitly be attributed to 
mesoscale eddies identified and tracked by Chelton et al. [2011a] but that two characteristics were inconsistent with their model of random eddies: the (i) variance of $\bar{u}$ did not decay as expected and (ii) number of eddies, as well as the size and amplitude of these eddies, correlated with the observed jet-like structures was large and broad in spectrum. These results indicate the observed structures may result from eddies of preferred paths. (Schlax and Chelton [2008] has provided a null hypothesis for testing whether or not observed patterns are the result of quasi-zonal jets. We emphasize that the model of random eddies was not intended to explain the observed patterns in their entirety. Despite this, their model-i.e., an asymptotic solution-and its predicted outcomes serve as useful benchmarks against which to compare the observations. Also note that we explored the statistical significance of patterns within the histograms of eddy positions, such as shown in Schlax and Chelton [2008, Figure 1a] with limited success owing to the finite number of eddies crossing a meridional cross section over the duration of the altimeter record.)

\subsection{Focus of This Study}

In this study, we use a fourth and independent data set to explore mesoscale jet-like structures in the ocean. We search for repeated mesoscale ocean fronts in microwave measurements of sea surface temperature (SST) and subsequently ask what gives rise to these fronts? While we are unable to demonstrate the existence of latent jets in the oceans owing to the prevalence of mesoscale eddies, there are several aspects of this study that make it attractive. First, mesoscale jet-like structures such as those documented above are not yet established to exist in microwave SST. Second, we employ a front detection algorithm designed to identify both strong and weak fronts [Cayula and Cornillon, 1992], potentially revealing latent jets. Third, temporal and spatial coverage of measurements made from the microwave sensor (described below) exceeds those made by both altimeter and floats. Fourth, observations of the structures in microwave SST could pave the way for longer-term studies involving infrared SST. This last point is pertinent because the temporal coverage of infrared SST extends from 1982 to the present and could prove useful in distinguishing between eddies of arbitrary and preferred paths. (The increased spatial resolution may also prove useful.) Finally, the study incorporates satellite altimeter and Argo measurements used in preceding studies providing a link between structures in SST and these data sets.

\subsection{Outline of the Study}

This paper is divided into six sections. We provide a brief background to the data sets in section 2, describe methods used in the study in section 3 , and present results of applying the algorithm to swath measurements of SST in section 4. Some modification of the algorithm is necessary for its application to microwave SST and this is detailed in Appendix A. We then examine short-duration (21 day) averages of the detections, isolate mesoscale fronts, and assess the primary (i.e., order-one) mechanism giving rise to repeated fronts in the subtropics. The implication, here, is that there may be an $O(\varepsilon), \varepsilon \ll 1$, signal that helps give rise to the patterns but we do not address this within the study. These analyses occupy the remainder of section 4. Finally, in section 5 we estimate the persistence of the patterns with averaging time in an effort to assess if/ where bands in SST and striations in SSH might be influenced by weak forcing mechanisms. The paper concludes with a discussion in section 6.

\section{Background}

Prior to describing methods, we provide a brief background to the primary and secondary data sets employed in the study.

\subsection{Microwave SST}

Passive microwave sensors are unique in their ability to measure ocean surface temperatures from space. While infrared measurements of SST are influenced significantly by atmospheric water vapor and clouds, microwave radiation emitted from Earth's surface penetrates clouds except in regions of heavy rainfall, providing an unhindered view of Earth for a large fraction of the time the sensor is in orbit. However, this advantage comes at a cost: upwelling radiation from Earth in the microwave portion of the spectrum is several orders of magnitude less than in the infrared band so that estimates of SST from microwave sensors require sampling from a larger area in order to obtain comparable thermal resolution. The Advanced Microwave Scanning Radiometer for the Earth Observing System (AMSR-E) sensor on-board the Aqua spacecraft had an effective footprint of $56 \mathrm{~km}$ [Chelton and Wentz, 2005], a swath width of approximately $1450 \mathrm{~km}$ [Martin, 2004] and provided approximately 89\% coverage of the globe each day and 98\% coverage every 2 days [Chelton and Wentz, 2005]. In contrast, the repeat orbit of satellite altimeters occurs at most once every 
10 days and distances between altimeter tracks can be large-e.g., greater than $300 \mathrm{~km}$ for TOPEX/Poseidon tracks [Chelton et al., 2001]. The merger and optimal interpolation of altimeter data overcomes this limitation to some degree by combining measurements from multiple spacecraft but assumes certain temporal and spatial decorrelation scales during interpolation [Ducet et al., 2000; Le Traon et al., 2003]. While studies have made use of microwave SST for understanding the temporal evolution of fronts, only a limited number of studies have used this data set to examine mesoscale fronts in the context of ocean circulation patterns. An example is that by Dong et al. [2006] who identify the Antarctic Polar Front and document its relationship to bathymetry in the Southern Ocean.

\subsection{Satellite Altimetry, MDT, and the Argo Observation System}

Satellite altimeters are conceptually simple instruments. They emit microwave radiation toward Earth from a known position in space and capture a portion of that radiation reflected from Earth's surface. From a knowledge of the speed of light in the atmosphere and the round-trip travel time of the emitted signal, one is able to estimate the distance between the satellite sensor and the ocean surface. Owing to a simple relationship between SSH gradients and ocean surface currents [Wunsch and Stammer, 1998] and the precise calibration, merger, and optimal interpolation of altimeter data from multiple platforms [Ducet et al., 2000; Le Traon et al., 2003], the altimeter has the ability to reveal mesoscale currents previously undetected by earlier ocean observations [Wyrtki et al., 1976]. (The relationship between SSH and near-surface currents is referred to as geostrophic balance and is simply the balance of Coriolis and pressure gradient forces in the horizontal momentum equations. A hydrostatic balance is assumed in the vertical. Mathematically, we write $u_{g}=-(g / f) \partial h / \partial y$ and $v_{g}=(g / f) \partial h / \partial x$. Here, $g$ is the acceleration due to gravity, $f$ is the Coriolis parameter, $h$ is the sea surface height, $x$ and $y$ are zonal and meridional distances, and $u_{g}$ and $v_{g}$ are zonal and meridional velocities, respectively. This balance is a very good approximation for near-surface currents averaged over horizontal distances of $30 \mathrm{~km}$ and/or time periods of 30 days or more.)

Despite that altimeters provide measurements of SSH with near-centimeter accuracy when averaged over spatial and temporal scales descriptive of the mesoscale [Cheney et al., 1994], they are incapable of depicting the oceanic mean dynamic height and associated mean circulation. The reason for this is that a time mean is subtracted from altimeter measurements in order to remove the near-constant effect of Earth's gravitational field on the ocean surface elevation. This demeaned altimetric signal is referred to as sea level anomaly (SLA). Instead, MDT (i.e., the mean SSH following removal of the geoid) is calculated through a synthesis of hydrographic, drifter, gravity, and wind data. Low-wave number undulations in MDT are accounted for using an accurate model of the geoid (owing to recent satellite gravity missions) while higher-wave number signals are estimated from hydrographic, drifter, and wind estimates by assuming a particular dynamical balance in the upper ocean [Maximenko et al., 2009; Rio et al., 2011]. MDT is now comparable in horizontal resolution to the merged SLA product such that, together, SLA and MDT provide a powerful tool for estimating mesoscale circulation patterns. We refer to the sum of SLA and MDT as absolute dynamic topography (ADT).

Complementary to these advances, the development and systematic deployment of Argo profiling floats have yielded an unprecedented view of upper ocean circulation. Each float spends the majority of its lifetime at fixed depths between 1000 and $2000 \mathrm{~m}$ and makes a complete profile of upper ocean temperature and salinity every 10 days. It subsequently relays this data via satellite to a receiving station, spending anywhere from 1 to $24 \mathrm{~h}$ at the ocean surface [Roemmich et al., 2001]. While intended for data assimilation and climate studies, the drift positions of the floats at parking depths have since been used to estimate circulation patterns at middepth [Cravatte et al., 2012; Park and Kim, 2013; Bostock et al., 2013].

\section{Methods}

\subsection{Details of the Data Sets Used in the Study}

The primary data used in this study are Level 2P swath measurements of SST from the AMSR-E sensor. For a definition of Level 2P products, see https://www.ghrsst.org/data/data-descriptions/l2p-observations/. We used those data distributed by Remote Sensing Systems (RSS) referred to as Version-7, which consist of swath measurements at a nominal resolution of $10 \mathrm{~km}$. Recall that the inherent resolution of AMSR-E SST is $56 \mathrm{~km}$ [Chelton and Wentz, 2005]. This data set is distributed with estimates of diurnal warming amplitude 
and, to eliminate fronts arising from such phenomena, we excluded from our analysis any pixel whose estimated diurnal warming amplitude exceeds $0.4^{\circ} \mathrm{C}$.

To complement these data, we examined (1) gridded SST, (2) gridded SSH, and (3) along-track SSH. The gridded AMSR-E SST data are also distributed by RSS and are provided on a $0.25^{\circ}$ grid at daily temporal resolution. These data were spatially filtered (described below) to isolate mesoscale signals and to help interpret repeated front detections found within swath data. We also estimated the persistence of zonal patterns with averaging period using the gridded SST and SSH data sets. Again, we excluded pixels whose estimated diurnal warming amplitude exceeds $0.4^{\circ} \mathrm{C}$.

The gridded SSH data used in this study are merged and optimally interpolated ADT distributed by Archivage, Validation, Interpretation des donnees des Satellite Oceanographiques (AVISO)/Collecte Localisation Satellites (CLS), referred to as the "reference series" and consist of the sum of altimeter-only sea level anomaly (SLA) and a 1992-2008 estimate of mean dynamic topography (MDT) [Rio et al., 2011]. We used the reference series as opposed to the updated series so as to maximize homogenous sampling over the record. The secondary form of SSH used in this study is along-track SLA from the Jason-1 spacecraft. (ENVISAT spacecraft measurements were examined as well, but yielded results nearly identical to those presented herein.) These SSH measurements represent a more fundamental altimeter product in many ways and are used to demonstrate that repeated front detections are associated with a dynamic signal and that amplitudes of SSH anomalies in the merged and optimally interpolated product are biased low. Gridded SSH are provided on a $0.25^{\circ}$ grid and resolve eddy-like anomalies with horizontal scales (a form of eddy radii) as small as 40-60 km, while along-track measurements are sampled at $1 \mathrm{~Hz}$ resulting in a nominal $10 \mathrm{~km}$ resolution product. We refer the reader to Chelton et al. [2011a] for a more complete discussion of the resolving capability of the merged and optimally interpolated product.

To help establish a connection between SST measurements made by the microwave sensor and SSH measurements made by the altimeter, we also obtained hydrographic profiles of ocean temperature in the top $1000 \mathrm{~m}$ made by vertically profiling Argo floats. Subtracting from these temperature profiles climatological estimates of temperature from the World Ocean Atlas 2009 (WOA2009) and averaging in equally spaced bins, we developed a three-dimensional (3-D) view of upper ocean temperature anomaly surrounding SST fronts. Since a similar technique has been used to characterize mesoscale eddies [see, e.g., Roemmich and Gilson, 2001; Chaigneau et al., 2011; Chelton et al., 2011b; Hausmann and Czaja, 2012] and results in a socalled composite eddy, we refer to this 3-D average-and the associated SST and SSH averages - as a composite front. We generate this composite for subtropical regions in the North and South Pacific, North and South Atlantic and Indian Oceans-regions defined later in the study. This analysis provides a remarkably consistent view of SST, SSH, and near-surface temperatures.

The primary data record is available from June 2002 to October 2011. (The AMSR-E antenna failed on 4 October 2011.) To reduce seasonal bias, we restricted analysis in this study to measurements made between June 2002 and May 2011.

\subsection{The Single Image Edge Detector}

We apply an ocean front detection algorithm [Cayula and Cornillon, 1992] to swath measurements of SST to investigate the existence of jet-like structures in the ocean. The motivation for using the detection algorithm is twofold. First, the detection algorithm does not depend upon previously employed filtering methods designed to isolate mesoscale features [e.g., Maximenko et al., 2008; van Sebille et al., 2011; Buckingham and Cornillon, 2013; also, see below]. Second, as noted earlier, the detection algorithm often identifies fronts associated with weak SST gradients. In contrast, fronts detected by thresholding SST gradient at a low threshold can result in spurious detections. Given the potential for latent jets to be found within the mesoscale eddy field [Berloff et al., 2011; Berloff and Kamenkovich, 2013a, 2013b], we feel this is an important distinction. The reason for using swath SST in place of mapped SST is that it reduces the potential for false detections to occur when applying the algorithm to gridded SST. These can occur, for example, when the algorithm encounters a portion of the mapped SST product that was measured at different times of a day. (Temperatures can be significantly altered relative to neighboring pixels either due to advection of surface temperatures or processes at the air-sea interface that may have changed over the course of the day. While we have attempted to eliminate detections resulting from or obscured by diurnal warming events by excluding pixel whose estimated diurnal warming amplitude exceeds $0.4^{\circ} \mathrm{C}$, the use of swath 
measurements helps eliminate artificial fronts forming at these data seams.) A brief description of the detection algorithm follows. For a more complete description, we refer the reader to Cayula and Cornillon [1992].

The algorithm, known as the Single Image Edge Detector (SIED), locally searches for temperature populations within an image. It consists of three steps: (1) histogram, (2) cohesion, and (3) contour following. In the first step, the SIED computes the histogram of temperatures within overlapping 32-by-32 pixel tiles (nominally $320-$ by- $320 \mathrm{~km}$ tiles for this data set). If the algorithm flags a tile as consisting of two populations, it then calculates the cohesion of the tile. The meaning of cohesion is best understood using the following two examples. A tile consisting of two temperatures, $T_{1}$ and $T_{2}$, in a checkerboard pattern is not cohesive; in contrast, a tile having an equal percentage of temperatures $T_{1}$ and $T_{2}$ but with the left-half equal to $T_{1}$ and the right-half equal to $T_{2}$ is cohesive. In identifying valid SST fronts, we wish to detect the latter of these while rejecting the former. Finally, if the tile passes both histogram and cohesion tests, those pixels having an immediate neighbor to the right or below that belongs to the other population are flagged as frontal pixels and a contouring algorithm connects and extends the pixels associated with this front segment.

A couple of remarks are necessary about the choice of tile size. First, its size is motivated by a need to accurately estimate the histogram; a smaller number of pixels results in a noisy histogram and poor performance. Second, while the choice of tile size impacts the size of fronts identified by the algorithm, the contour-following step lessens this effect by connecting frontal pixels between neighboring tiles. We now discuss the computation of front probability, a step that helps identify repeated front detections made over a given time period.

\subsubsection{SST Front Probability}

Since swath measurements of SST are provided by RSS at nominally $0.1^{\circ}(10 \mathrm{~km})$ resolution, we binned front detections onto a $0.1^{\circ} \times 0.1^{\circ}$ grid and calculated SST front probability as the number of detections divided by the number of clear SST pixels identified within each bin. Clear pixels are those pixels identified as "excellent" by RSS (proximity confidence flag $=4$ ) and model diurnal warming amplitude less than $0.4^{\circ} \mathrm{C}$. Defined in this manner, SST front probability is a function of latitude, longitude, and averaging period for the given space-time bin. We produce estimates of this variable both for multiyear (2002-2011) and 21 day (21 d hereafter) averaging periods. While we demonstrate the existence of bands in multiyear averages of SST front probability, we focus our attention on the shorter-duration averages since only a limited number of studies have considered this shorter time scale [e.g., Maximenko et al., 2005] and the ambiguity introduced by westward-propagating eddies is removed. Here we assume the position and amplitude of mesoscale eddies do not vary much over this period, an assumption supported by observations [Chelton et al., 2011a]. An estimate of eddy translation distance over this period at midlatitudes is $\left(2 \mathrm{~km} \mathrm{~d}^{-1}\right)(21 \mathrm{~d}) \approx 42 \mathrm{~km}$, or 45 pixels.

\subsubsection{Application of the SIED to Microwave SST}

Two factors must be considered when applying the SIED to microwave SST. The first is that AMSR-E data are distributed in along and cross-scan coordinates. Because coordinates are not, in general, orthogonal, care must be taken to ensure front probabilities computed from detections of the SIED are consistent with those obtained using orthogonal coordinates. This has been done. The second factor that should be considered is the effect of large-scale temperature gradients on detector performance. During the course of this study, the SIED was found to detect fronts more readily in the presence of a background temperature gradient owing to the histogram-nature of the algorithm. This likely does not occur when applying to infrared SST owing to increased levels of white noise in the data sets (see Appendix A). To reduce the sensitivity of the algorithm, it was modified so that the background gradient itself (defined as the gradient of a plane fit to the $64 \times 64$ pixel region about the tile) does not result in front detections. This is described in Appendix $A$.

\subsubsection{Identifying Repeated Fronts in Short-Duration ( 21 d) Averages}

To gain an understanding of the oceanographic processes giving rise to the bands, we examined spatially filtered SST and SSH within the reference frame of these structures. Below, we describe an automated procedure for identifying peak contours in $21 \mathrm{~d}$ estimates of SST front probability.

Peak contours or bands were identified in $21 \mathrm{~d}$ estimates of SST front probability. We first applied a median filter to SST front probability by replacing each pixel with the median value of front probability within a $1^{\circ}$ 


\section{CAGU Journal of Geophysical Research: Oceans}

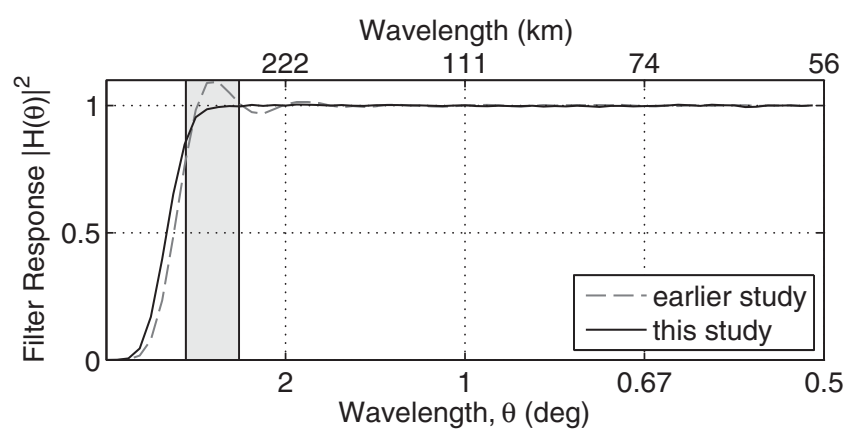

Figure 1. Effective magnitude-squared response of the high-pass filtering method used in this study. The filter is nearly isotropic in latitude and longitude in units of ${ }^{\circ}$. Wavelengths in units of $\mathrm{km}$ assume $1^{\circ}=111.2 \mathrm{~km}$ and, thus, correspond to meridional distances. The shaded region highlights wavelengths of $300-500 \mathrm{~km}$. For convenience, this filter response is compared with that used in an earlier study [Buckingham and Cornillon, 2013]. by $1^{\circ}$ window centered on the pixel. We then computed a "standard normalized" version of SST front probability by (i) calculating the mean and standard deviation of SST front probability within $4^{\circ} \times 4^{\circ}$ windows centered on each pixel, (ii) subtracting the mean from each value of front probability, and (iii) dividing this result by the standard deviation. Thresholding this image at a value of 0.1 provided a mask which we then applied to SST front probability to isolate the bands. We

used a density-based clustering algorithm [Ester et al., 1996; Daszykowski et al., 2001] to identify pixels having statistically similar latitudes and longitudes and, although computationally expensive, this step provided an objective method of identifying bands. Lastly, the positions of the bands were defined by the mean latitude of pixels within a given longitude bin and resulting positions were smoothed with an approximate $0.3^{\circ}$ moving-average filter. Those bands whose latitudinal variance exceed $1^{\circ}$ were excluded from the analysis, a step which was implemented to eliminate wildly varying shapes that often resulted from the connection of unrelated but neighboring contours in front probability.

\subsection{Spatial Filtering Applied to Gridded SST and SSH}

We apply a spatial high pass filter to gridded SST and gridded ADT in order to isolate eddies and jets from background processes. This step preserves mesoscale features $O(50-400 \mathrm{~km})$ while removing largescale lateral gradients present in the data and is ultimately helpful in interpreting front detections. The filter is different from that used in earlier studies [Maximenko et al., 2008; Buckingham and Cornillon, 2013] and results in a smoother filter response (Figure 1). The filtering process begins with application of a spatial low pass filter, we subtract the smoothed field from the original data and repeat these steps a second time. This implements a spatial high pass filter twice. (A single-step filtering process that achieves the same filter response requires a considerably higher-order filter and increases processing time.) The low pass filter is a two-dimensional, nearly isotropic (in units of degrees), minimum four term Blackman-Harris window [Harris, 1978] with $N=51$. It has an effective cutoff wave number of $4.5^{\circ}$ which is defined as the wavelength at which the filter has gain equal to 0.71 (i.e., $3 \mathrm{~dB}$ below the maximum gain).

In the work that follows, we examine the persistence of the bands with averaging period. We computed the mean (i.e., time-averaged) meridional SST gradient for the period June 2002 to May 2011, examine the decay of its amplitude with averaging period and compare this with a similar estimate from mean zonal geostrophic velocity, $\bar{u}$, estimated from SSH. In each case, we estimate these quantities from the spatially filtered gridded SST and SSH fields described above. Note, this parallels earlier work used to reveal striations [Maximenko et al., 2008; van Sebille et al., 2011; Buckingham and Cornillon, 2013], as well as persistence in time using SSH [Buckingham and Cornillon, 2013].

In summary, swath SST measurements are used with the front detection algorithm and in the demonstration of quasi-zonal bands in time-averaged SST gradient magnitude (2002-2011) without applying the high pass filter. In all other places (e.g., composite and persistence estimates), we used the gridded SST product and apply the spatial high pass filter described above.

\section{Results}

In this section, we demonstrate the existence of zonal bands in multiyear averages of SST front probability and SST gradient magnitude. We examine short-duration averages of SST front probability and search for mechanisms giving rise to repeated fronts (i.e., bands). While the existence of latent jets cannot conclusively 
be proven, we find that repeated front detections in short-duration averages result from neighboring eddies of opposite polarity more often than not. Furthermore, we demonstrate that large gradients within the bands propagate westward at the eddy speed and can explain $20 \%$ of the variance in the zonal bands in a multiyear average of SST gradient magnitude.

\subsection{Observed Multiple Quasi-Zonal Bands}

Figure 2 displays (a) average SST gradient magnitude, (b) SST front probability, and (c) normalized SST front probability determined from microwave SST measurements, 2002-2011. The normalization method follows that described in section 3.2.3. In all fields, one observes zonally elongated structures regularly separated in space in all major ocean basins. Spectral analysis of the fields reveals that the signals in the subtropics are characterized by peak energies near meridional wavelengths of $400 \mathrm{~km}$ and zonal wavelengths exceeding $1500 \mathrm{~km}$ (Figure 3), implying a near-zonal orientation of the bands and meridional separations between bands of 350 and $400 \mathrm{~km}$. These characteristics are consistent with jet-like structures observed in MDT [Maximenko et al., 2008]. Lastly, we illustrate SST front probability computed for a $21 \mathrm{~d}$ period in Figure 4. Again, there appear to be ubiquitous bands in all ocean basins with regular spacing in the meridional direction.

\subsection{Mean Dynamic Signature Associated With the Bands}

We first demonstrate that the bands are, on average, associated with a dynamic height signature indicative of zonal jets. We accomplished this in the following manner. We (1) identified the positions of repeated fronts (i.e., bands) in 21 d estimates of SST front probability during 2002-2011 (section 3.2.3), (2) identified along-track altimeter measurements made while crossing these positions and at these times, and (3) averaged altimeter measurements as a function of distance from the bands. This was done for regions in the North Pacific $\left(20^{\circ} \mathrm{N}-45^{\circ} \mathrm{N}, 180^{\circ} \mathrm{E}-230^{\circ} \mathrm{E}\right)$ and South Pacific $\left(20^{\circ} \mathrm{S}-50^{\circ} \mathrm{S}, 200^{\circ} \mathrm{E}-280^{\circ} \mathrm{E}\right)$. Our motivation for using SST front probability is that it provides a cleaner field from which to isolate and identify the bands when compared with SST gradient magnitude. Our reason for using along-track measurements is that there are considerably fewer assumptions made within these data when compared with optimally interpolated $\mathrm{SSH}$.

Figure 4c illustrates the result of applying the band-identification method to a $21 \mathrm{~d}$ estimate of SST front probability in the regions of interest in the North and South Pacific; i.e., the first step in the process. While the method excludes some of the more prominent bands in front probability, the bands retained for subsequent analysis (solid black lines in Figure 4c) match those of Figure $4 \mathrm{~b}$ well. In summary, Figure 4 and similar graphics suggest the skeletons of bands in $21 \mathrm{~d}$ estimates of SST front probability are well defined.

After identifying the positions of the bands and along-track measurements intersecting these bands, we projected each along-track SSH profile onto a line perpendicular to the band and further limited analysis to altimeter tracks intersecting bands at angles $45^{\circ}<\theta<135^{\circ}$, where $\theta$ is the angle made with respect to the band, positive counter-clockwise from east. Data were binned as functions of distance from the band (positive equatorward) and averaged to produce the mean SSH profiles (Figure 5).

While considerable spread exists within SSH measurements, mean profiles depict a dynamic signature associated with the bands. A simple model of mean SSH across the bands can be obtained by applying a nonlinear least squares regression to the data of the form $h=a \tanh \left[\left(x-x_{0}\right) / b\right]$, where $a, b$, and $x_{0}$ are estimated parameters. Doing so for the North Pacific yields $a=2.05 \mathrm{~cm}, b=43.4 \mathrm{~km}$, and $x_{O}=12 \mathrm{~km}$ and results in a curve nearly indistinguishable from the mean profile. While a dynamic signature is implied by the lateral gradient of SSH profiles, it is nonetheless instructive to compute the corresponding geostrophic current. Using a constant Coriolis parameter of $f=10^{-4} \mathrm{~s}^{-1}$ and defining $x_{b}$ as the across-band distance, the associated along-band geostrophic velocity, $u_{b}^{\prime}=(g / f)\left(\partial h / \partial x_{b}\right)$, is a maximum of $4.6 \mathrm{~cm} \mathrm{~s}^{-1}$ at a position $12 \mathrm{~km}$ equatorward of the band and is directed primarily eastward. A similar regression for the South Pacific yields $a=2.81 \mathrm{~cm}, b=42.2 \mathrm{~km}$, and $x_{o}=5.5 \mathrm{~km}$. The associated along-band geostrophic velocity is also directed eastward and is a maximum of $6.5 \mathrm{~cm} \mathrm{~s}^{-1}$ at a position $5.5 \mathrm{~km}$ equatorward of the band. Note, the amplitude of the along-band velocity is greater in the South Pacific than North Pacific and both graphics depict slight equatorward shifts of the front. To summarize, bands in $21 \mathrm{~d}$ averages of front detections are associated with approximately eastward-flowing currents and we observe a slight equatorward shift of the front in both hemispheres. 


\section{QAGU Journal of Geophysical Research: Oceans}
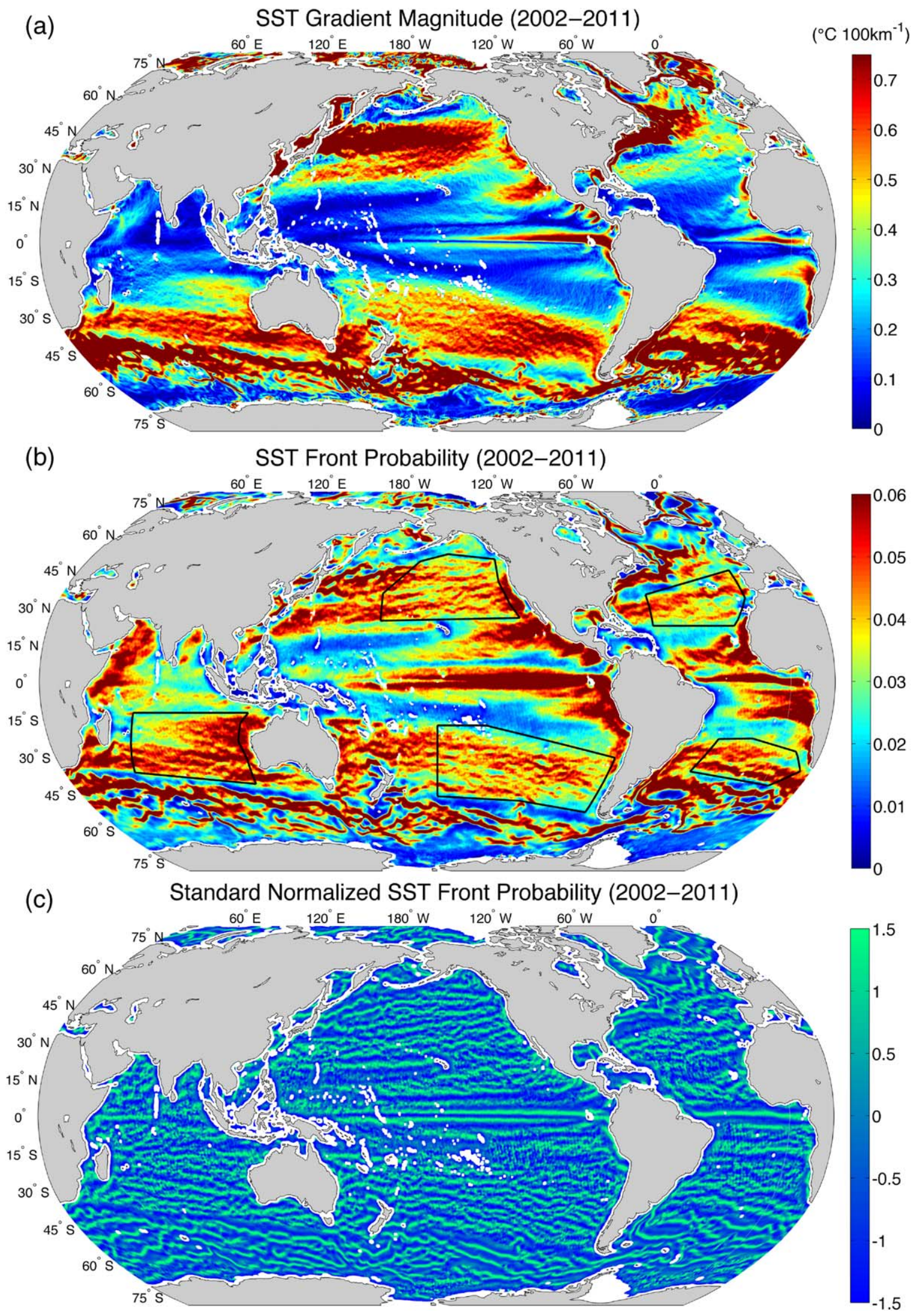

Figure 2. (a) SST gradient magnitude, (b) SST front probability, and (b) standard normalized SST front probability (June 2002 to May 2011 ). Normalization was performed by subtracting from each pixel the local mean and dividing by the local standard deviation within a $4^{\circ} \times 4^{\circ}$ window. Black lines in Figure $2 \mathrm{~b}$ denote five subtropical regions examined in section 4.3 . 


\section{QAGU Journal of Geophysical Research: Oceans}
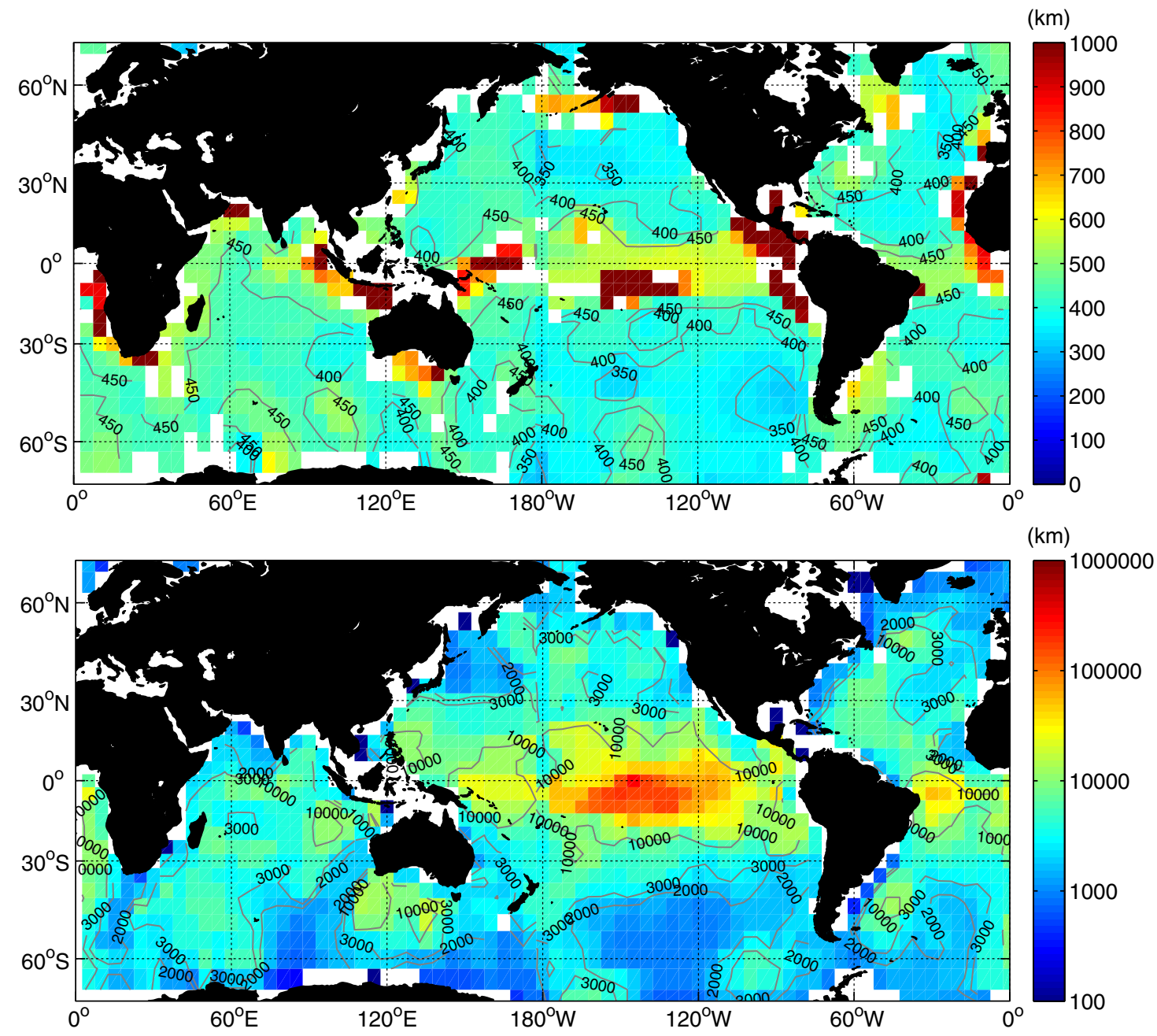

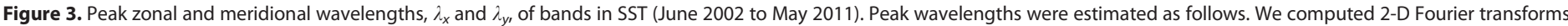

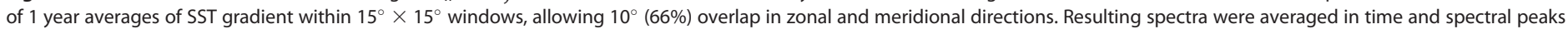
were located. Wavelengths exceeding $1500 \mathrm{~km}$ should be regarded only qualitatively.

\subsection{What Gives Rise to Repeated Fronts in Short-Duration Averages?}

In this section, we examine bands in short-duration averages in greater detail. By making use of gridded SST and SSH data sets and by centering our coordinate system on gradients found within bands in SST, we obtain two-dimensional (2-D) composites of SST and SSH from which we infer processes giving rise to the bands. Furthermore, we average Argo temperatures in this coordinate system, providing information about the vertical structure of the bands.

Figure 6 illustrates spatially filtered SST and the skeletons of identified bands (cf. Figure 4c) identified from swath data in the South Pacific. In addition, we display contours of spatially high pass filtered SSH. Several characteristics are evident in this graphic. First, the identified locations of bands appear to separate positive and negative SSH anomalies. Second, mesoscale SST and SSH appear tightly correlated; the correlation coefficient is $\rho=0.53$ for this snapshot. Third, the magnitudes of SST anomalies are greatest on the western sides of closed contours in SSH. In other words, the extrema in SST anomalies appear shifted west of extrema in $\mathrm{SSH}$ anomalies. Fourth, the geostrophic velocities associated with the bands are predominantly directed eastward (not shown). While there is some indication of an organized eddy field-e.g., a train of anticyclonic eddies can be seen at approximately $33^{\circ} \mathrm{S}, 220-250^{\circ} \mathrm{E}$ - it is nonetheless difficult to discern clear evidence of jets. The implication is that if multiple zonal jets exist in the ocean, they must be latent [Berloff et al., 2011]. We demonstrate these characteristics in an average sense below. 


\section{QAGU Journal of Geophysical Research: Oceans}

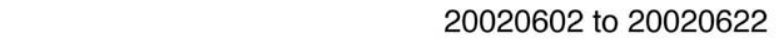

(a)

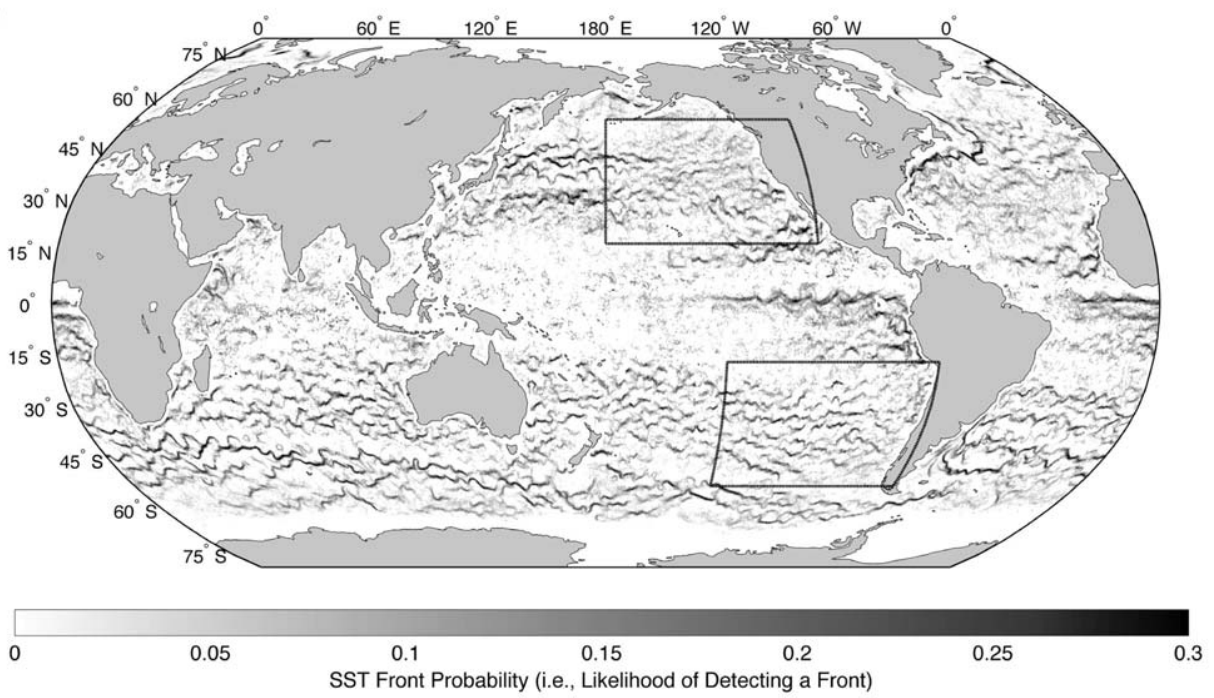

(b)
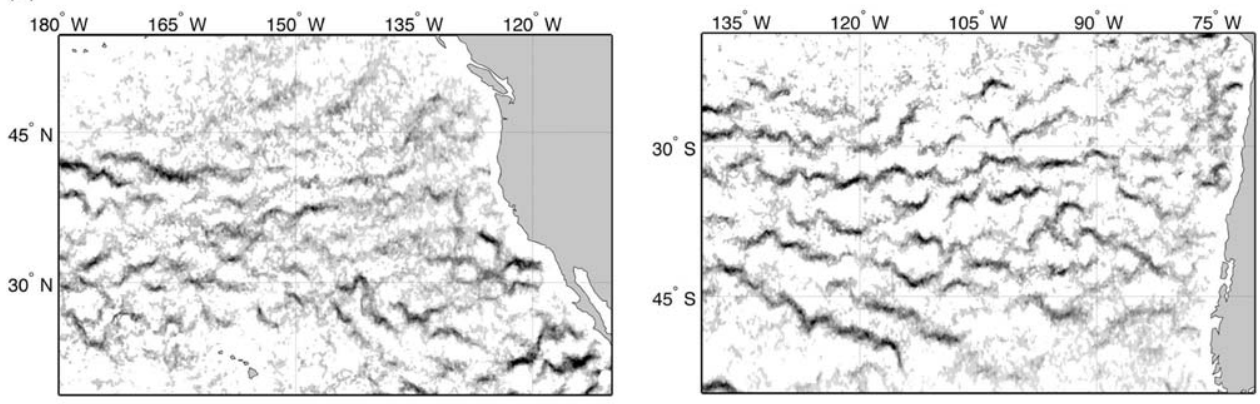

(c)
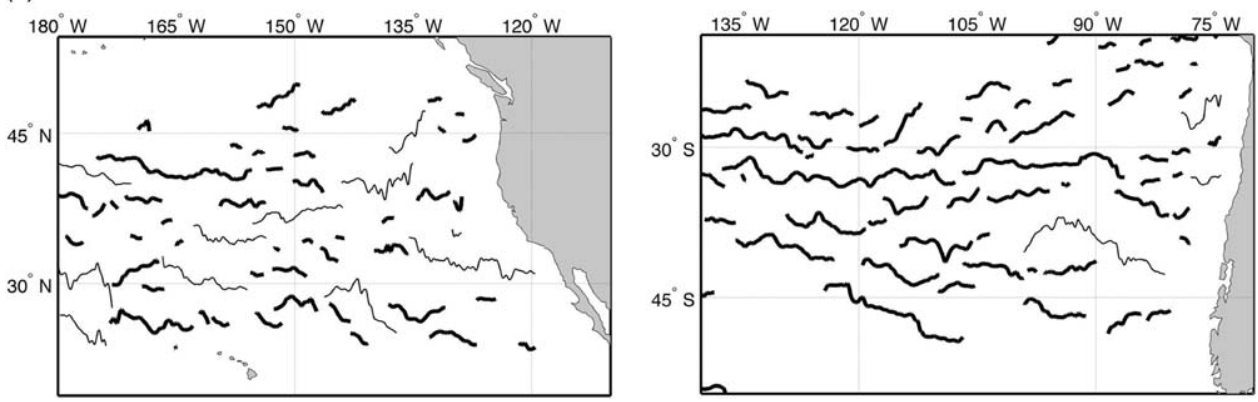

Figure 4. (a) SST front probability estimated from front detections during a 21 day period centered on 12 June 2002. (b) Magnified regions in the North and South Pacific. (c) Result of applying the band-identification procedure described in section 3.2.3; heavily shaded lines denote bands retained for analysis in this study, while lightly shaded lines illustrate those bands excluded from analysis. Note that the averaging period illustrated here corresponds to an austral winter so we expect a greater number of fronts in the Southern Hemisphere.

\subsubsection{Composites of SST and SSH in the Vicinity of Large SST Gradients}

In this analysis, we examine SST and SSH in the vicinity of large SST gradients observed in five subtropical basins illustrated in Figure 2b. A preliminary version of this research based on a single year (June 2002 to May 2003) was presented by Buckingham and Cornillon [2010]. Here, we examine the full SST record (2002-2011).

We introduce the term high gradient event (HGE) to refer to a particular class of mesoscale SST gradients that occur relatively infrequently but that appear correlated with the bands identified above. Specifically, HGEs are defined as gradients whose across-band SST gradient exceeds a threshold above the background gradient and that reside within the bands. (One might more generally define HGEs as the set of connected pixels whose gradient magnitude exceeds a threshold but we restrict ourselves to a subset of these events-i.e., those found within the identified bands.) Thresholds were selected such that the integrated 

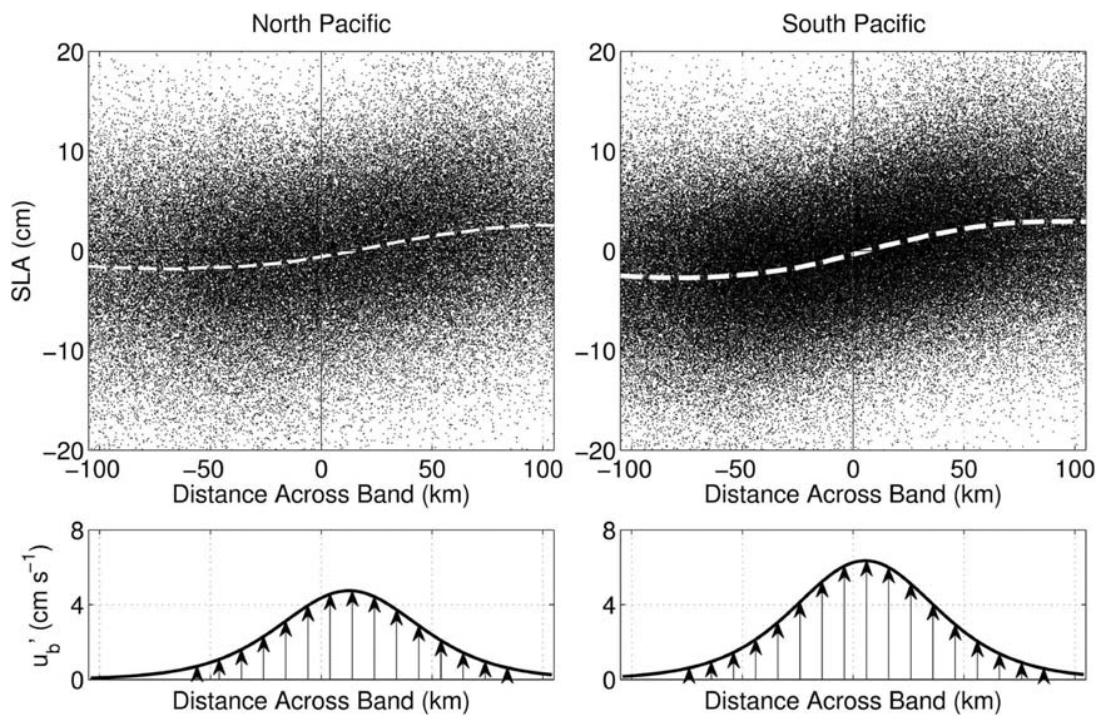

Figure 5. Along-track altimeter measurements as a function of across-band distance in the North and South Pacific from the Jason-1 spacecraft. Black dots depict $1 \mathrm{~Hz}$ along-track SLA measurements crossing bands in SST front probability and projected onto lines orthogonal to the band; dashed white lines denote mean profiles. For illustration purposes, we also display the mean geostrophic velocity along the band assuming a Coriolis parameter of $f=10^{-4} \mathrm{~s}^{-1}$. Across-band distance is defined as positive equatorward, bin-widths are $10 \mathrm{~km}$ and the minimum number of observations in any bin is $\sim 14,000$. Mean SSH profiles in North and South Pacific regions are associated with maximum geostrophic velocities of approximately 4.6 and $6.5 \mathrm{~cm} \mathrm{~s}^{-1}$ at distances 12 and $5.5 \mathrm{~km}$ equatorward of the bands, respectively.

probability above these thresholds yielded approximately the same value for each basin-i.e., $\int_{a_{i}}^{\infty} P_{i}(x) d x=0.06$, where $a_{i}$ are thresholds corresponding to each basin. For example in the South Pacific, we used an across-band temperature gradient threshold near $0.007^{\circ} \mathrm{C} \mathrm{km}^{-1}$. For each $\mathrm{HGE}$, we constructed a coordinate system whose $x$ and $y$ axes were tangent and perpendicular to the band at the HGE location, respectively (Figure 7). The orientation of the $y$ axis was defined so that it points nominally northward.

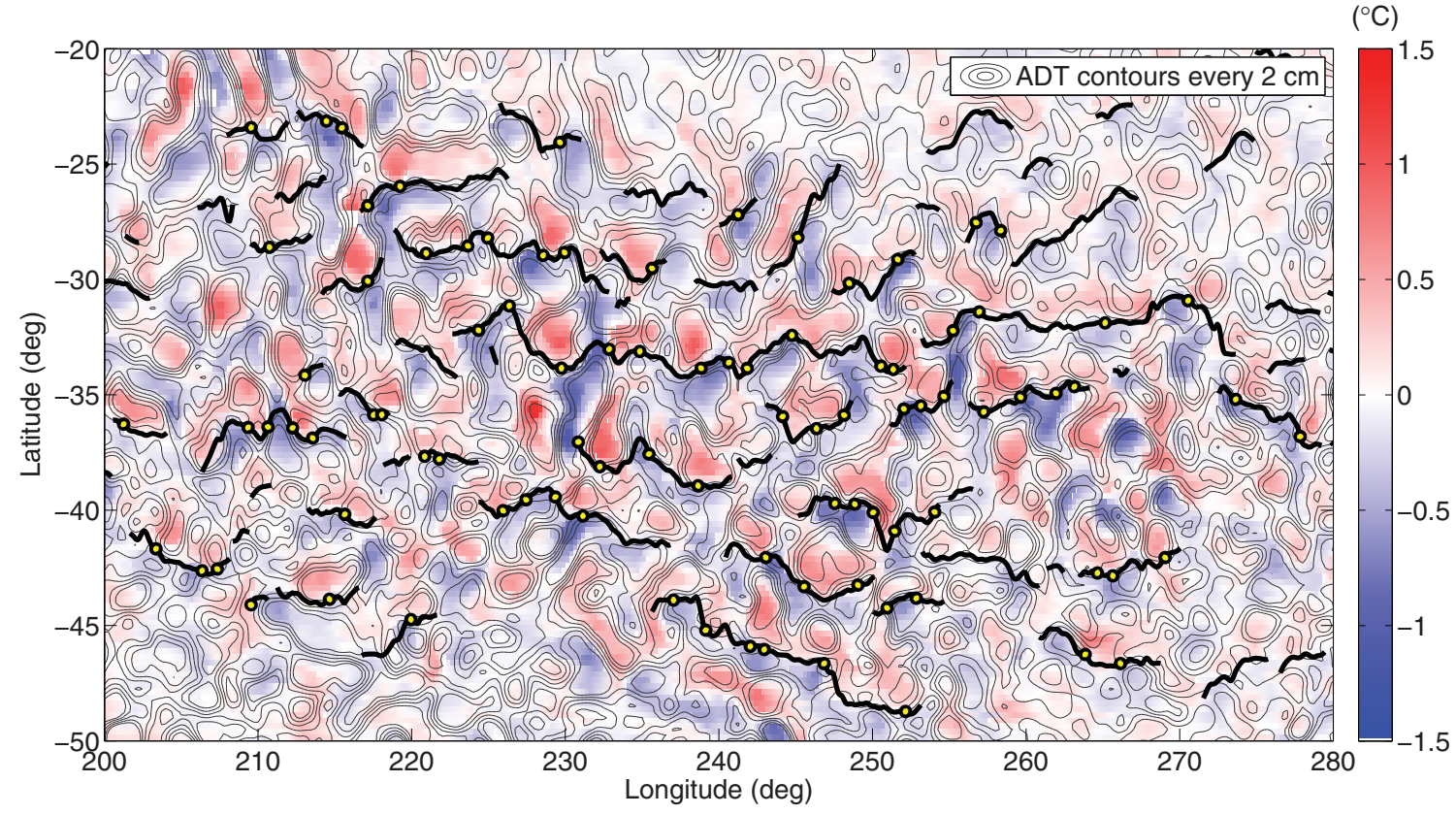

Figure 6. Spatially filtered SST (color; 7 day average valid 12 June 2002) with spatially filtered SSH in the form of ADT (contours; valid 12 June 2002) in the South Pacific. Skeletons of zonal bands in SST front probability (black; 21 day average valid 12 June 2002) are displayed, as well as HGEs (see section 4.3). Contours of ADT range between $\pm 4 \mathrm{~cm}$. 
Figure 8 displays the histogram of the direction of $y$ axes in each basin and depicts a predominant northward direction to the reference system.

The across-band SST gradient, SST anomaly, and SSH anomaly were interpolated to an equal-area grid centered on the HGEs, each having dimensions of $300 \times 300 \mathrm{~km}$. Here, we use the terms SST and SSH anomaly to refer to spatially high pass filtered SST and SSH, respectively. Averages of SST gradient, SST anomaly, and SSH anomaly were obtained for the five subtropical basins using data from 2002 to 2011 and are shown in Figure 9. We also identified and averaged along-track Jason-1 altimeter measurements falling within the vicinity of HGEs in the South Pacific for comparison with the gridded product (Figure 10). In all cases, we highlight minima and maxima within each field and the average along-band $(x)$ positions of extrema in SSH anomaly. Finally, we illustrate the along-band surface geostrophic velocity, $u_{b}^{\prime}$, as a function of distance across the band and evaluated at the mean $x$ position of extrema in SSH. We also highlight locations of velocity maxima.

Several characteristics are observed in Figures 9 and 10. First, note that SST gradient contains a peak at the origin and falls off with distance from this location, consistent with a field properly averaged in a coordinate system centered on HGEs. Moreover, the falloff is greater in the $y$ direction than the $x$ direction, suggesting that the coordinate system was properly aligned relative to the band. Second, SST anomaly displays an antisymmetric structure about the extremum in SST gradient, with warm anomalies equatorward and cool anomalies poleward of HGE centroids. Third, SSH anomaly depicts a similar geometrical structure, consisting of a positive (anticyclonic) anomaly on the equatorward side and negative (cyclonic) anomaly on the poleward side. However, the antisymmetric structure in SSH differs from that in SST in that the axis of the dipole-like pair in SSH is shifted 30-60 km east of the pair in SST. There is also a consistent equatorward shift of SSH with respect to SST in all basins and is manifest as a meridional shift of the front. Recall that a similar feature was observed in Figure 5. Fourth, estimates of the SSH structure obtained from along-track altimeter data compare well with those obtained from merged altimeter data (Figure 10) but amplitudes in the along-track average are $20 \%$ larger. This may be notable since it suggests processing methods applied to altimeter data when producing the gridded product reduces the signal magnitude.

\subsubsection{Composites of Argo Profiles in the Vicinity of HGEs}

To obtain information about the vertical structure of the gradient events, we obtained and processed temperature measurements made by Argo profiling floats in the vicinity of HGEs. First, each Argo float that appeared within the $300 \times 300 \mathrm{~km}$ region defined by an HGE and within $\pm 3.5 \mathrm{~d}$ of the event was placed in the aggregated region. Second, each Argo profile was interpolated to an evenly spaced depth grid and the nearest WOA2009 climatological profile (in latitude, longitude, and time-of-year) was subtracted from this temperature profile. Finally, anomalous temperature profiles were binned and averaged to produce 3-D composites of temperature surrounding HGEs. We applied a $3 \times 3$ median filter to temperature anomalies at each depth to reduce speckle.

The first column of Figure 11 displays the locations of Argo profiles (dots) corresponding to each mean field. Colored plots to the right display horizontal slices of these composites at depths of 20, 200, and $1000 \mathrm{~m}$. In Figures 12a-12c, we display the vertical cross sections of temperature anomaly in the South Pacific since it is here that the number of Argo profiles is greatest. These are cross sections taken at (a) $y=75 \mathrm{~km}$, (b) $y=-75 \mathrm{~km}$, and (c) $x=40 \mathrm{~km}$, which is approximately through the centers of the anticyclone and cyclone. Finally, in Figure 12d, we display the along-band geostrophic velocity, $u_{b}^{\prime}$, associated with Figure $12 \mathrm{c}$ and representative of the South Pacific region. We provide this to explicitly illustrate the meridional shift of currents with depth. To compare the subsurface structure with surface elevations measured by the altimeter, we plot above these cross sections contours of depth-integrated temperature anomaly and average SSH anomaly evaluated at these locations. Temperature-derived contours were obtained by integrating the Argo-derived temperature anomalies from $1500 \mathrm{~m}$ to the surface. Integration from $600 \mathrm{~m}$ to the surface yields comparable results. We overlay SST contours for reference.

One observes in Figure 11 that the axis of the eddy pair is centrally located at $20 \mathrm{~m}$, moves along the band in a nominally eastward direction at $200 \mathrm{~m}$ and can be found east of this location at greater depths. The dipole-like structure even appears coherent at $1500 \mathrm{~m}$ depth (not shown). This shift with depth is also observed in vertical cross sections of the eddies (Figures 12a and 12b). Composites reveal a "slab-like" structure in the upper ocean confined to the top $100 \mathrm{~m}$. Shifts of temperature anomaly in the cross-band 


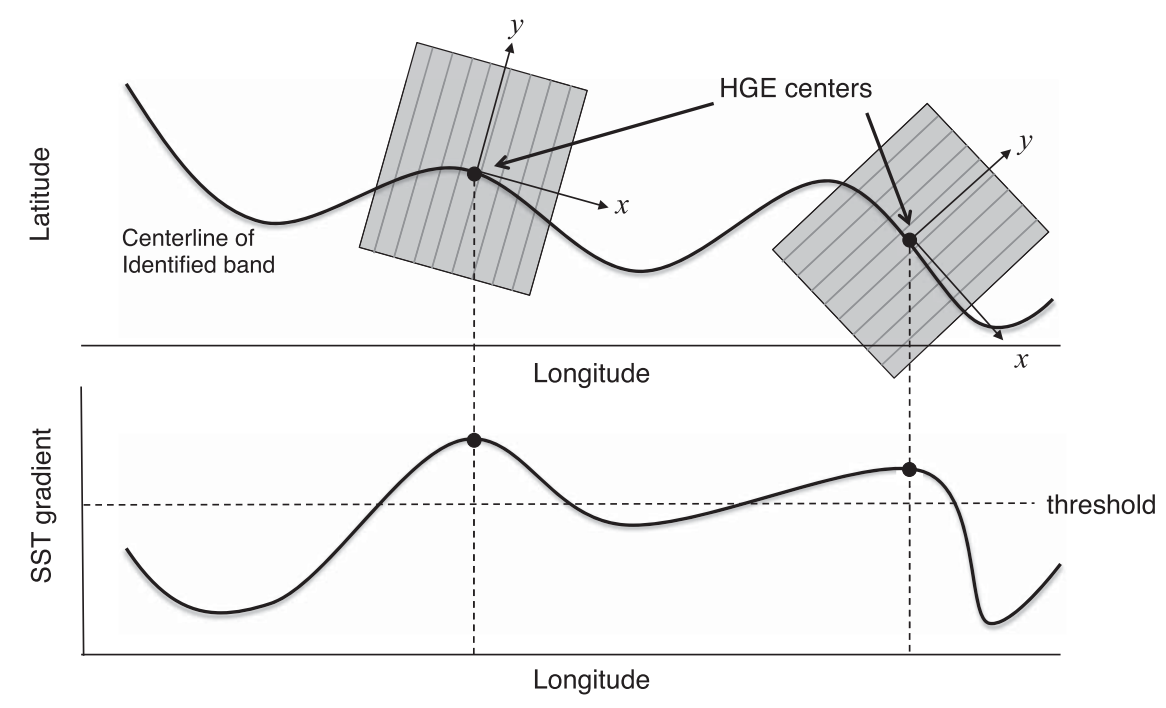

Figure 7. Illustration of HGEs identified from the position of bands and across-band SST gradient, and the construction of a coordinate system centered on HGEs. Coordinates $x$ and $y$ define orthogonal distances in along and across-band directions, respectively. HGEs are defined as extrema in the across-band gradient.

direction are also observed (Figure 12c). Here, the horizontal gradient of temperature anomaly associated with anticyclonic and cyclonic eddies appears to migrate in the positive cross-band direction with increasing depth. This is consistent with the offset between SST and SSH noted earlier (Figure 5) and is reflected in the along-band geostrophic velocity fields (Figure 5, lower plot and Figure 12d, here). This nominally corresponds to a meridional migration of the front with depth (cf. Figure 8). Lastly, the depth-integrated temperature contour in both zonal and meridional cross sections has shape nearly identical to SSH. This agreement between Argo-derived and primarily altimeter-derived anomalies supports the notion that altimeter measurements are largely reflective of first-mode baroclinic and surface-trapped processes [Wunsch, 1997; Lapeyre, 2009].
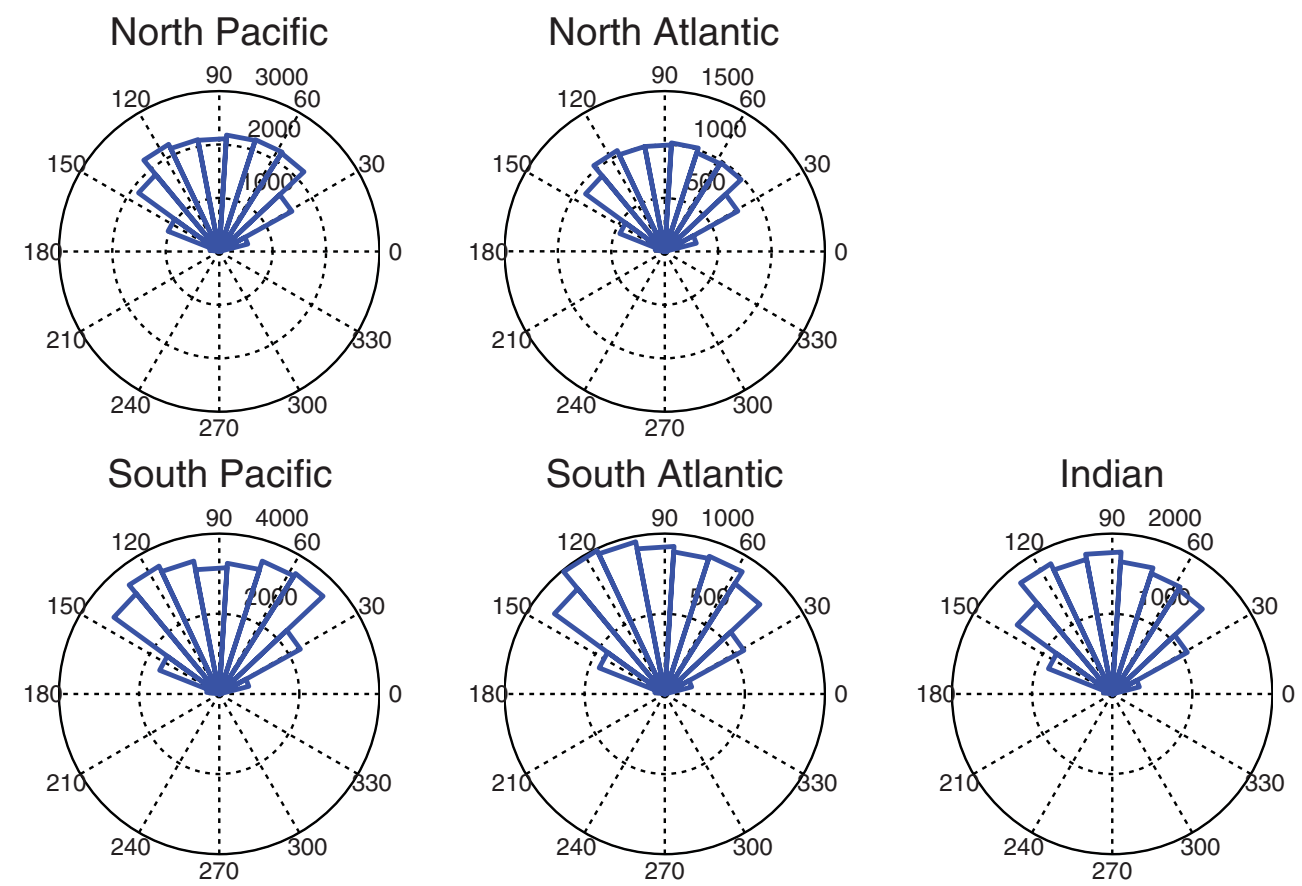

Figure 8. Histograms of the direction of the across-band coordinate system (i.e., the $y$ axis in Figure 7). Angles of $0^{\circ}$ and $90^{\circ}$ correspond to eastward and northward directions, respectively. 

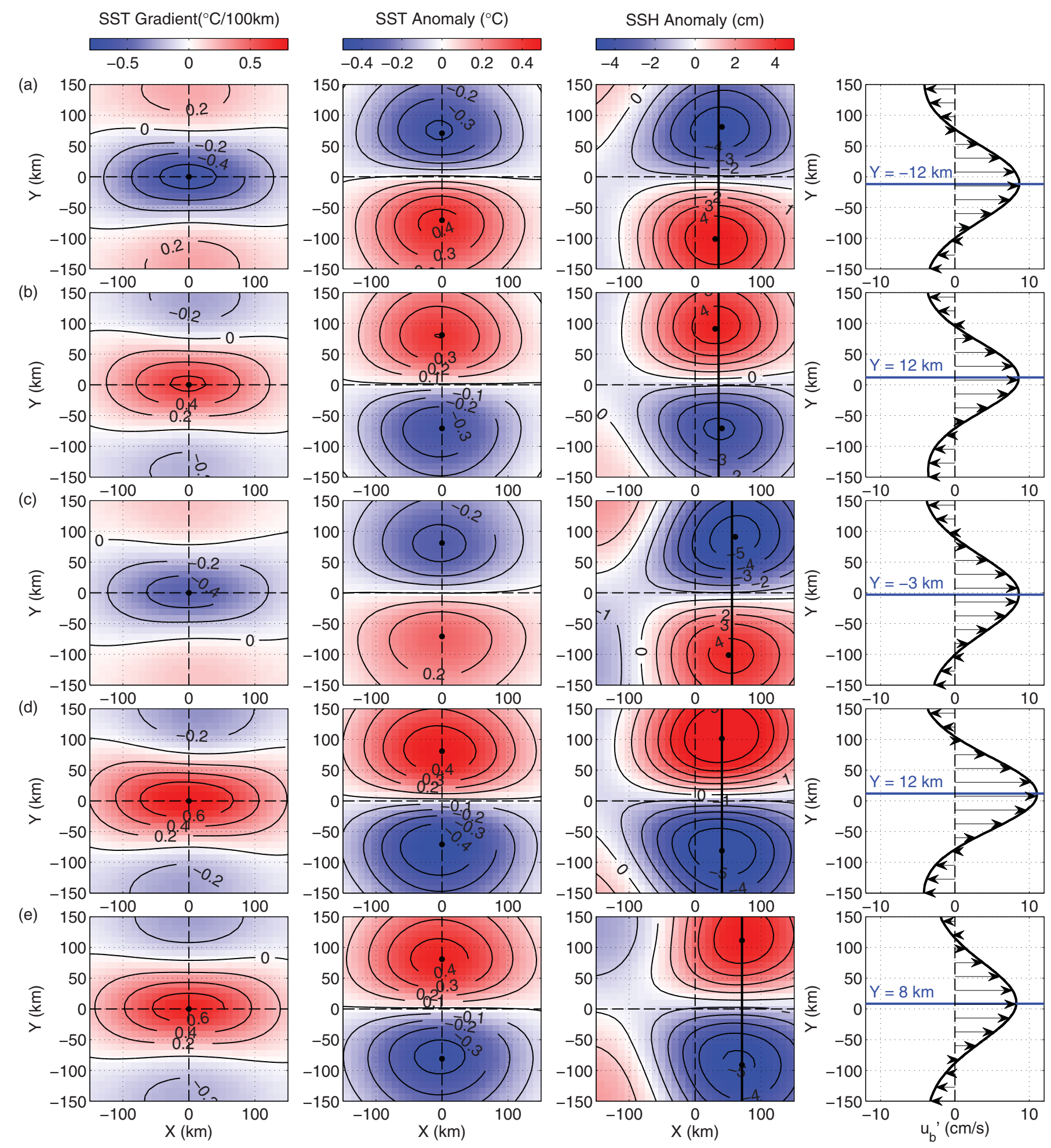

Figure 9. (columns 1-3) Composites of across-band SST gradient, SST anomaly, and SSH anomaly obtained when averaging within a coordinate system centered on HGEs (June 2002 to May 2011). Subtropical basins include (a) North Pacific, (b) South Pacific, (c) North Atlantic, (d) South Atlantic, and (e) Indian Oceans. Coordinates $x$ and $y$ are distances in the along and across-band directions, respectively. Black dots denote extrema, vertical solid lines shown in SSH anomaly denote the mean $x$ position of the eddy-like pair in SSH. (column 4) Along-band surface geostrophic velocity evaluated from SSH anomaly at the mean $x$ position of the eddy-like pair. Blue line and text depict the across-band shift of the dynamic front. We assumed $f=10^{-4} \mathrm{~s}^{-1}$. 


\section{QAGU Journal of Geophysical Research: Oceans}

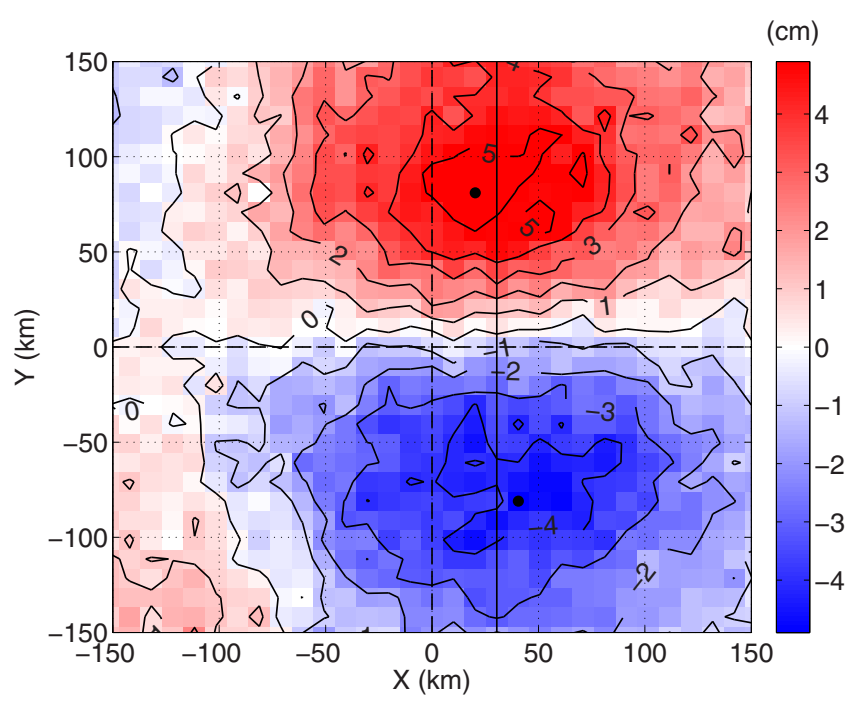

Figure 10. Composite of SSH anomaly obtained when averaging along-track altimeter measurements in the South Pacific in a coordinate system centered on HGEs (June 2002 to May 2011). Altimeter measurements are those from the Jason-1 spacecraft in the form of SLA. This composite can be compared with that obtained using the gridded altimeter product (cf. Figure 9b, column 3).
The above relationship between SST, SSH, and subsurface temperature anomaly can be understood by examining the nearly 2-D geostrophic flow associated with the anomalies (D. Chelton, personal communication, 2010). While not shown, the geostrophic current is along lines of constant SSH and is clockwise for positive SSH anomalies and counter-clockwise for negative SSH anomalies in the Northern Hemisphere; the opposite is true in the Southern Hemisphere. This gives rise to a net eastward flow between the eddies. West of the maximum gradient in SST, there is a convergence of meridional flow toward the $x$ axis, advecting

warm water from the equatorward side and cool water from the poleward side, while currents to the east advect warm and cool waters parallel to and away from this axis. This results in little or no SST gradient east of the origin but a large SST gradient at the origin. At greater depths, the background gradient is smaller and the more dominant signal giving rise to temperature gradients is the contrast of the eddies themselves - that is, the signal primarily reflected in altimeter measurements.

That two mechanisms give rise to temperature anomalies and that their intensities vary with depth can explain the zonal shift of the eddy structure with depth (cf. Figures 12a and 12b) and thus the zonal offsets between SSH and SST. It is likely that other processes occurring at the air-sea interface help shape the appearance of composites. For example, surface heat fluxes and mixing may play significant roles. The relative importance of such processes might best be diagnosed by simplified models in which neighboring eddies are embedded in a background temperature gradient whose magnitude varies with depth. Such a model might be improved further by including a seasonal cycle to the temperature gradient.

\subsubsection{A Cautionary Note Regarding Frontal Composites}

The results presented above lead us to conclude that HGEs result from neighboring mesoscale eddies. However, there is ambiguity in these composites that make interpretation challenging. For example, a positive anomaly located equatorward of the HGE $50 \%$ of the time and a negative anomaly located poleward of the HGE $50 \%$ of the time but with equal magnitude can give rise to the same pattern. To this end, we quantified the fraction of the time HGEs are associated with individual eddies and pairs of eddies. This is explained below.

We approximated the location of eddies by the positions of extrema in both SST and SSH. We first identified minima and maxima of SST and SSH contained within a rectangular region centered on an HGE. The rectangular region had dimensions $L_{x}=300 \mathrm{~km}$ and $L_{y}=400 \mathrm{~km}$, where $x$ and $y$ denote along-band and crossband directions, respectively. We additionally required that the extrema have magnitudes exceeding $4 \mathrm{~cm}$ and $0.4^{\circ} \mathrm{C}$. We recognize this choice of threshold is rather arbitrary but it is necessary to ensure SST/SSH contours are circular in shape. For cases in which oppositely signed extrema are found within this region and above the preceding thresholds, we stipulate that a line drawn between the extrema be perpendicular to the band. Finally, if an extrema pair meets these criteria, we say that the HGE results from an eddy pair; otherwise, the HGE is described as resulting from a single eddy or no eddy at all.

Our results indicate that HGEs are associated with a single SSH extremum $42-50 \%$ of the time and a pair of SSH extrema $45-58 \%$ of the time (Table 1). The numbers are more variable in SST. There, we find that HGEs 

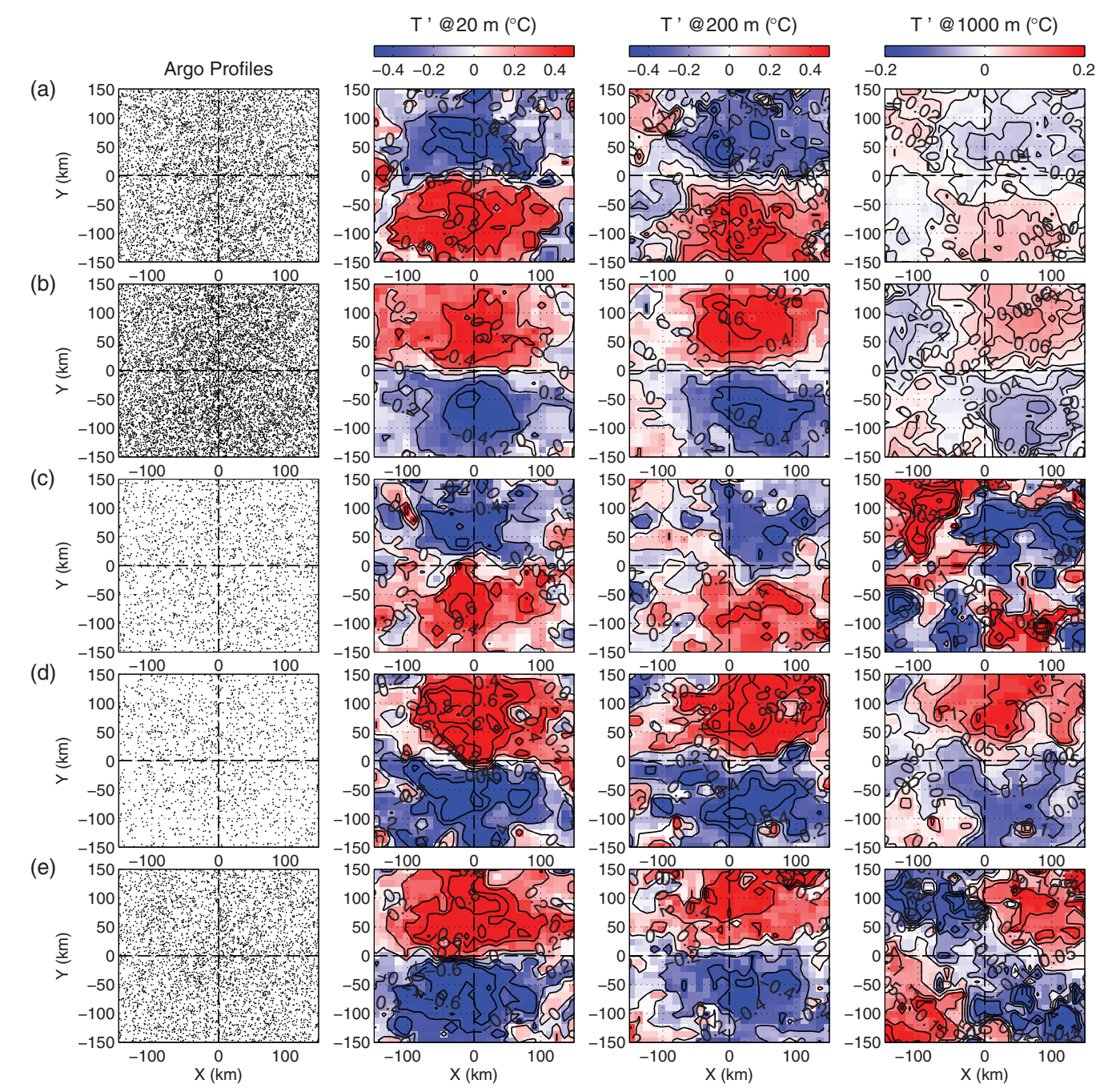

(a)
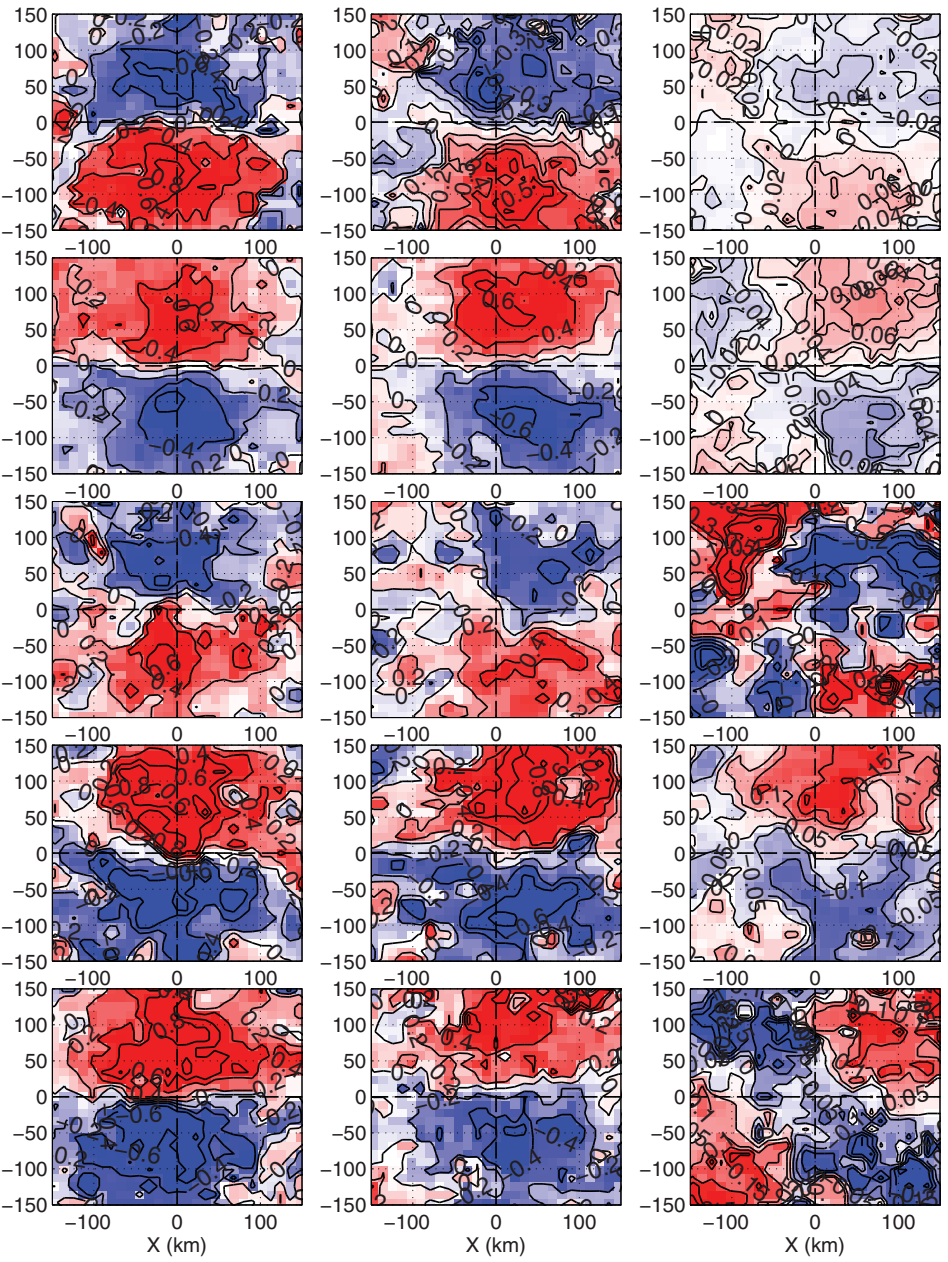

Figure 11. Composites of temperature anomaly from Argo profiles (June 2002 to May 2011) at depths of 20, 200, and 1000 m when averaged within a coordinate system centered on HGEs. In the left column, we illustrate positions of profiles at $1000 \mathrm{~m}$ depth. Basins (a)-(e) as in Figure 9 and $x$ and $y$ are distances in the along and across-band directions, respectively. Temperature anomalies are defined relative to the WOA2009 climatology.

are associated with a single extremum $0.46-75 \%$ of the time and a pair of extrema $23-57 \%$ of the time. For both SSH and SST cases, there are virtually no instances in which HGEs are not associated with at least one extremum. In addition, when HGEs are associated with pairs of extrema, the distribution of the ratio of their amplitudes is heavily weighted toward -1 , illustrating that extrema are comparable in magnitude and opposite in sign. Thus, while one cannot make conclusive statements regarding HGEs from the composites alone, the combination of Figure 6 (and similar images) and Table 1 suggests HGEs result from neighboring eddies more often than not.

An explanation offered for the observed discrepancy between columns 2 and 4 in Table 1 is that processes affecting SST are different than those modifying SSH. Surface winds give rise to shear stresses, leading to breaking waves and inducing mixing of warm surface and cool subsurface waters. At larger scales, winds drive vertical fluxes via Ekman convergence/divergence and can enhance heat flux between the ocean and atmosphere. These processes alter the temperature of the sea surface and will likely modify mesoscale signals correlated with eddies. In contrast, SSH as measured by the altimeter is largely insulated from such phenomena. Thus, we expect wind-generated perturbations and associated heat fluxes to account for much of the discrepancy in Table 1. For a more detailed discussion of processes modifying SST, we refer the reader to Katsaros [1980] and Martin [2004]. 


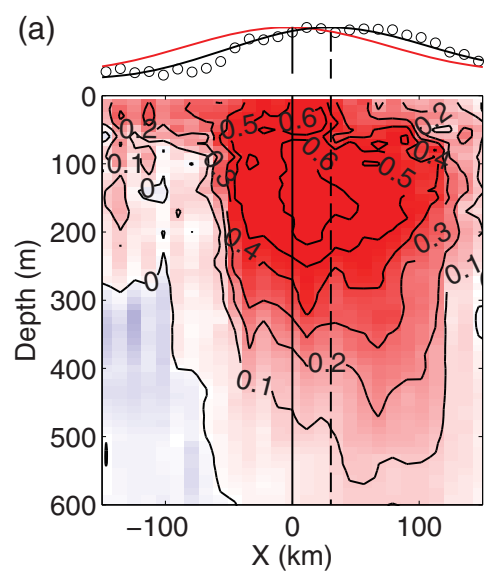

(b)
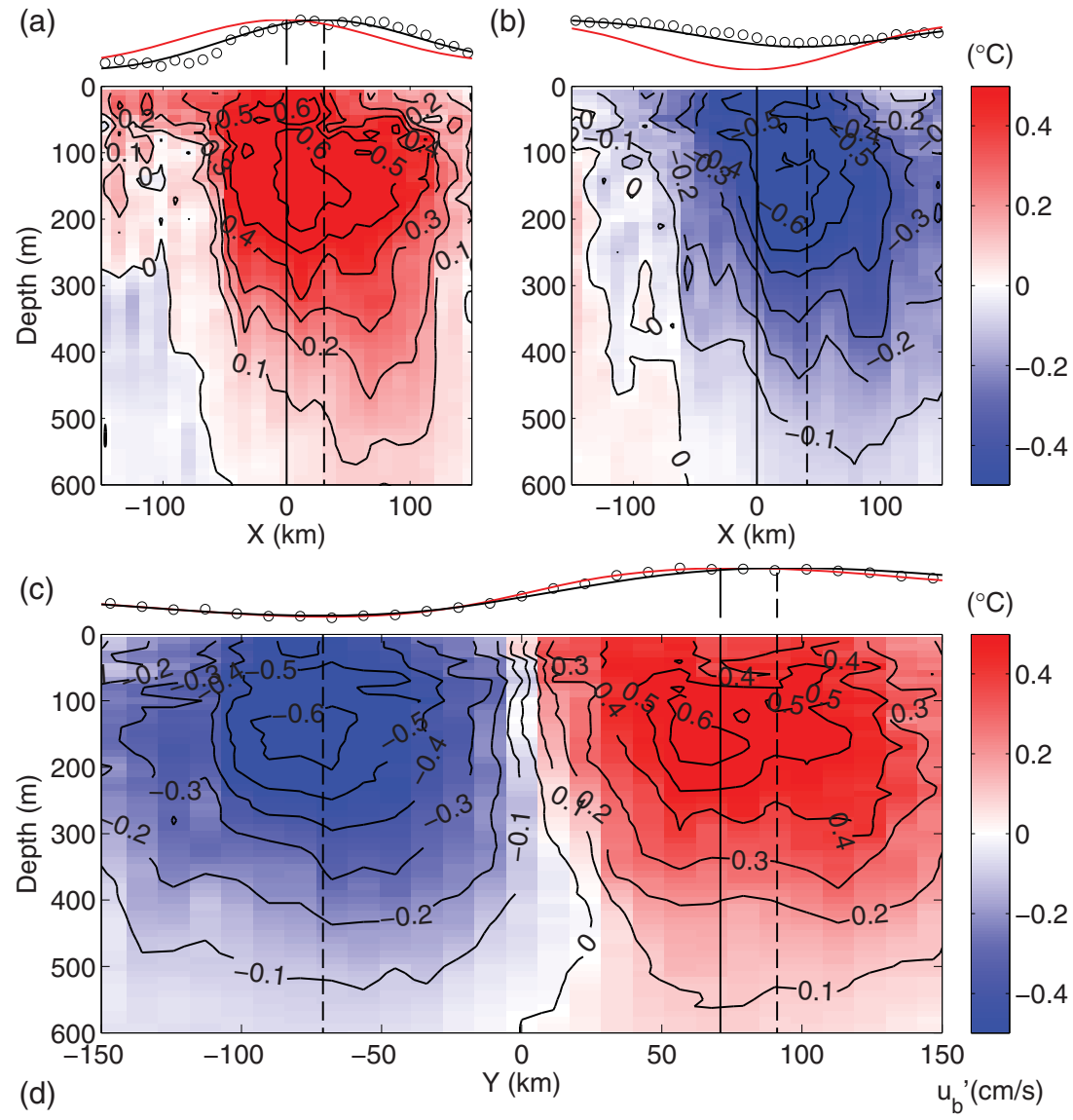

(d)

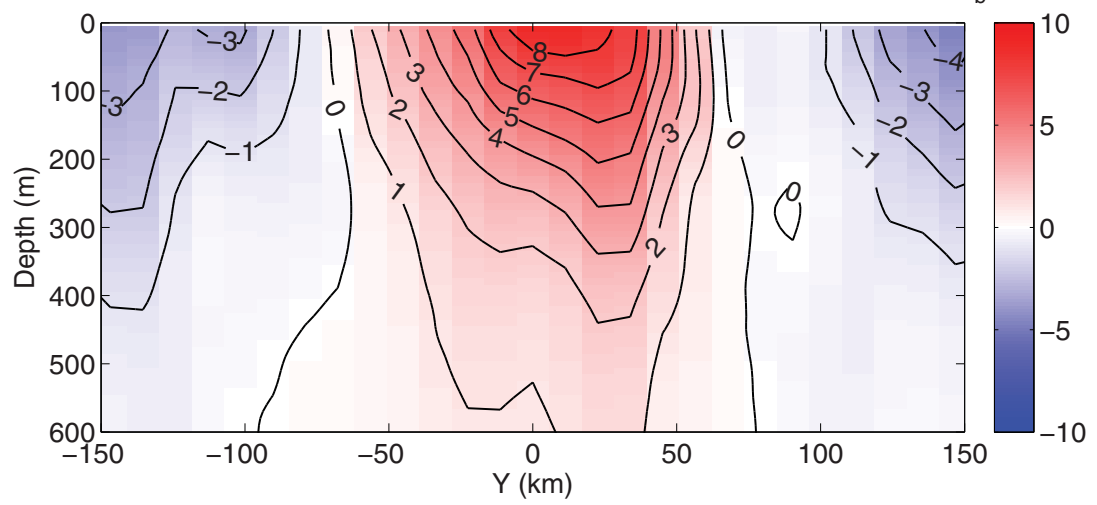

Figure 12. Composites of temperature anomaly from Argo profiles in the South Pacific: vertical cross sections at (a) $y=75 \mathrm{~km}$, (b) $y=-75 \mathrm{~km}$, and (c) $x=40 \mathrm{~km}$ (cf. Figures $9 \mathrm{~b}$ and $11 \mathrm{~b}$ ). Above each plot, we display contours of SST anomaly (red line), SSH anomaly (black line), and vertically integrated temperature anomaly (circles). Vertical lines denote the positions of extrema in SST and SSH and $x$ and $y$ are distances in the along and across-band directions, respectively. (d) Along-band geostrophic flow at $x=40 \mathrm{~km}$, positive out of the page. Thermal winds were estimated assuming constant salinity ( $35 \mathrm{psu})$, a June climatological temperature profile from WOA2009, $f=10^{-4} \mathrm{~s}^{-1}$ and no motion at $1500 \mathrm{~m}$ depth.

\subsubsection{Fraction of Variance in Zonal Bands Due to HGEs}

Buckingham and Cornillon [2013] showed that propagating eddies were a significant contributor to the variance associated with striations determined from SSH fields and they argued that this contribution arose both because of the number of eddies and because of their westward propagation. Because HGEs occur in patterns resembling quasi-zonal bands one is led to ask: what fraction of observed zonal bands can be explained by HGEs?

Prior to addressing this question however, we first note that HGEs propagate westward, as do eddies discussed in Buckingham and Cornillon [2013]. We determined this by binning the positions of HGEs as a 


Table 1. Fraction of HGEs Associated With a Single Eddy and Pair of Eddies
\begin{tabular}{lcccc} 
Region & Single (SST) & Pair (SST) & Single (SSH) & Pair (SSH) \\
\hline North Pacific (NP) & 0.57 & 0.43 & 0.55 & 0.45 \\
South Pacific (SP) & 0.60 & 0.39 & 0.48 & 0.52 \\
North Atlantic (NA) & 0.75 & 0.23 & 0.48 & 0.52 \\
South Atlantic (SA) & 0.46 & 0.54 & 0.42 & 0.58 \\
Indian (I) & 0.49 & 0.51 & 0.49 & 0.51 \\
\hline
\end{tabular}

sequential positions of eddy centers tracked by Chelton et al. [2011a] and subsequently smoothed using a 3 pixel (21 d) moving-average filter. Only eddies with lifetimes $\geq 16$ weeks were considered in order to obtain reliable estimates of eddy speed.

To quantify the fractional variance of bands explained by HGEs, we computed SST gradient magnitude from $7 \mathrm{~d}$ averages of swath measurements, set pixels within a radius $R=150 \mathrm{~km}$ from HGEs equal to the background gradient at these locations and averaged in time. The resulting multiyear average was then compared with those containing HGEs (cf. Figure 2a). (The background SST gradient was estimated by removing a spatially high pass filtered SST field from averages of swath SST. The spatial filter is characterized by the frequency response shown in Figure 1 but has order $N=129$ to accommodate the higherresolution grid of the swath data.) From these two mean fields, we found that the fraction of variance explained by HGEs in SST gradient magnitude is $0.14-0.23$. Replacement of $R$ by 100 and $200 \mathrm{~km}$, respectively, yielded fractions of $0.10-17$ and $0.17-0.28$, respectively.

\section{Persistence in Time}

A useful benchmark for evaluating the statistical randomness of the upper ocean is provided by Schlax and Chelton [2008]. Developing a model of SSH determined by mesoscale eddies, Schlax and Chelton demonstrate that westward-propagating eddies produce a time-averaged zonal geostrophic velocity field, $\bar{u}$, whose standard deviation decays as $T^{-0.5}$, where $T$ is the averaging period. In this model, the eddies have Gaussian shape and initial position sampled from a uniform distribution, and $\bar{u}$ is determined from the meridional gradient in SSH. In an analogous manner, one can develop a model of westward-propagating SST anomalies, where SST anomalies have Gaussian shape and initial position sampled from a uniform distribution. The standard deviation of time-averaged meridional SST gradient likewise decays as $T^{-0.5}$. (Here, we correct an oversight in our earlier study owing to a presumed typographical error in Schlax and Chelton [2008]. We find that the standard deviation of $\bar{u}$ predicted by a model of randomly positioned eddies should decay as $T^{-0.5}$ instead of $T^{-1.0}$, where $T$ is the averaging period.) In light of the work of Schlax and Chelton [2008] and the near-analogous relationship between SST and SSH, a useful quantity in assessing the "randomness" of the upper ocean is the decay of standard deviation of meridional SST gradient with averaging period.

We perform a regression of the standard deviation as a function of averaging period using the following functional form: $\sigma=\alpha T^{\prime}$. Here, $T$ is the averaging period, $\alpha$ is a measure of the magnitude of the variable of interest at $T=0$ (but not relevant for the present study), and $\gamma$ is a measure of its persistence with averaging period. The motivation for using this form is that it encompasses a diverse range of signals. A value of $\gamma=0$ indicates a stationary signal; $\gamma=-0.5$ indicates a time-averaged field statistically indistinguishable from a field of eddies with initial position sampled from a uniform distribution [Schlax and Chelton, 2008]; and values between these limits indicate signals with some measure of likelihood in space.

We computed the standard deviation of time-averaged meridional SST gradient with respect to a spatial mean and estimated persistence, $\gamma$, using $15^{\circ} \times 15^{\circ}$ tiles with $50 \%$ overlap. An equally valid definition of standard deviation is one defined relative to a meridional mean - that is, a mean taken over several degrees of latitude. In light of this, we computed $\gamma$ based on this definition but found no considerable difference between the two estimates. We computed the standard deviation for averaging periods $T=4$ weeks, 1, 2, 3, and 4 years in an effort to reduce seasonal bias and regressed this quantity as a function of averaging period. See Buckingham and Cornillon [2013, Figure 8], for an example of such regression applied to SSH. Since the altimeter provides a longer record from which to estimate persistence, we also performed this regression on zonal geostrophic velocity, $\bar{u}$, estimated from ADT and compared this to the value from SST. 


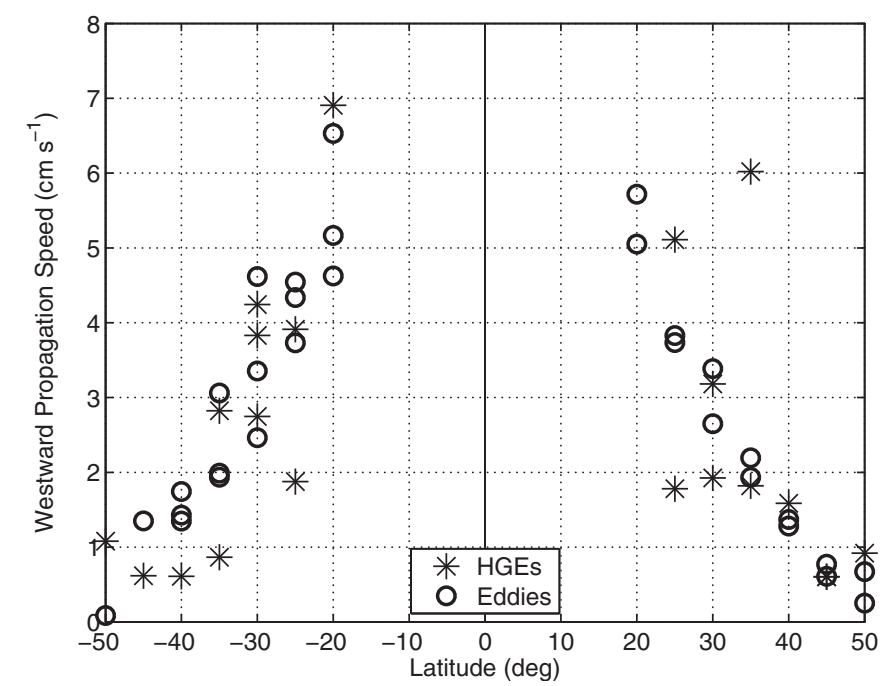

Figure 13. Westward propagation speeds of HGEs and mesoscale eddies in the subtropics. HGE speeds were estimated from the Radon transform of time-longitude histograms of HGEs, 2002-2011. Mean eddy propagation speeds were estimated from sequential positions of eddies in a database of tracked eddies [Chelton et al., 2011a] and were smoothed using a three point (i.e., $21 \mathrm{~d}$ ) moving-average filter.
For simplicity, we refer to persistence in meridional SST gradient as $\gamma_{S S T}$ and that in zonal geostrophic velocity from $\mathrm{SSH}$ as $\gamma_{S S H}$.

Figure 14a displays $\gamma_{S S T}$ and $\gamma_{S S H}$ estimated for the global ocean. In addition, in Figure 14b, we display a scatterplot of $\gamma_{S S T}$ versus $\gamma_{S S H}$. The results indicate a close relationship between the two variables, with $\gamma_{S S T}$ slightly higher (although we have not addressed the significance of that difference) and all values well above -0.5 . As one might expect, larger values (i.e., more positive) of $\gamma_{S S T}$ and $\gamma_{S S H}$ are observed in strong current regions such as western boundary currents, equatorial regions and in the Southern Ocean, and smaller values in the subtropics where the field is dominated primarily by mesoscale eddies. The correlation coefficient between the two quantities is 0.80 and a least squares regression of $\gamma_{S S T}$ as a function $\gamma_{S S H}$ gives a near one-to-one relationship.

\section{Discussion}

Microwave SST, SSH, and Argo float data all tell a consistent story. Repeated fronts within the subtropics appear as quasi-zonal bands in a multiyear (2002-2011) average of the detections and similar patterns are seen in SST gradient magnitude. These fronts arise primarily due to contrasting warm and cool temperature anomalies, where horizontal advection by mesoscale eddies likely plays a role. Furthermore, temperature gradients between these anomalies (i.e., HGEs) propagate westward at eddy speeds (cf. Figure 13) and contribute approximately $20 \%$ to the observed variance in multiple quasi-zonal bands. These results support the notion that oceanic jet-like structures are due, at least in part, to westward-propagating mesoscale eddies [Schlax and Chelton, 2008; Scott et al., 2008]. Thus, while relying on ancillary data sets (altimeter, MDT and Argo) for interpretation of SST, this finding confirms an earlier result obtained using SSH measurements, alone [Buckingham and Cornillon, 2013].

Another result of this study is that bands in SST are more persistent than might be the case if patterns were generated by randomly located propagating eddies. This persistence is also seen in SSH and suggests a degree of order to the surface ocean. To what degree remains a topic for debate. Progress in interpreting striations and bands further might be made by examining their position relative to bottom topography [Scott et al., 2008]. Indeed, locations of jet-like structures in the South Pacific appear influenced by bathymetric features [cf. Buckingham and Cornillon, 2013, Figure 12] and maps of persistence (cf. Figure 14) contain the suggestion of topographic influence, particularly in the Southern Ocean. Another avenue that could be explored is estimates of persistence using infrared SST. Owing to the longer infrared SST record (1982-present), this could lead to a more robust estimate of persistence.

It is difficult to say from the preceding analysis whether or not multiple zonal jets exist in the oceans. That the identified fronts in this study do not explain the entire portion of the observed variance is not surprising. We expect eddies of smaller amplitude and that modify the SST field to a lesser extent to make up a portion of the observed variance. That being said, $21 \mathrm{~d}$ averages of the detections contain zonally elongated structures (cf. Figure 4) and composites of across-band SST gradient (cf. Figure 8, column 1) depict an elongated structure whose principal axis is in the along-band direction. These results may indicate eddies 


\section{QAGU Journal of Geophysical Research: Oceans}
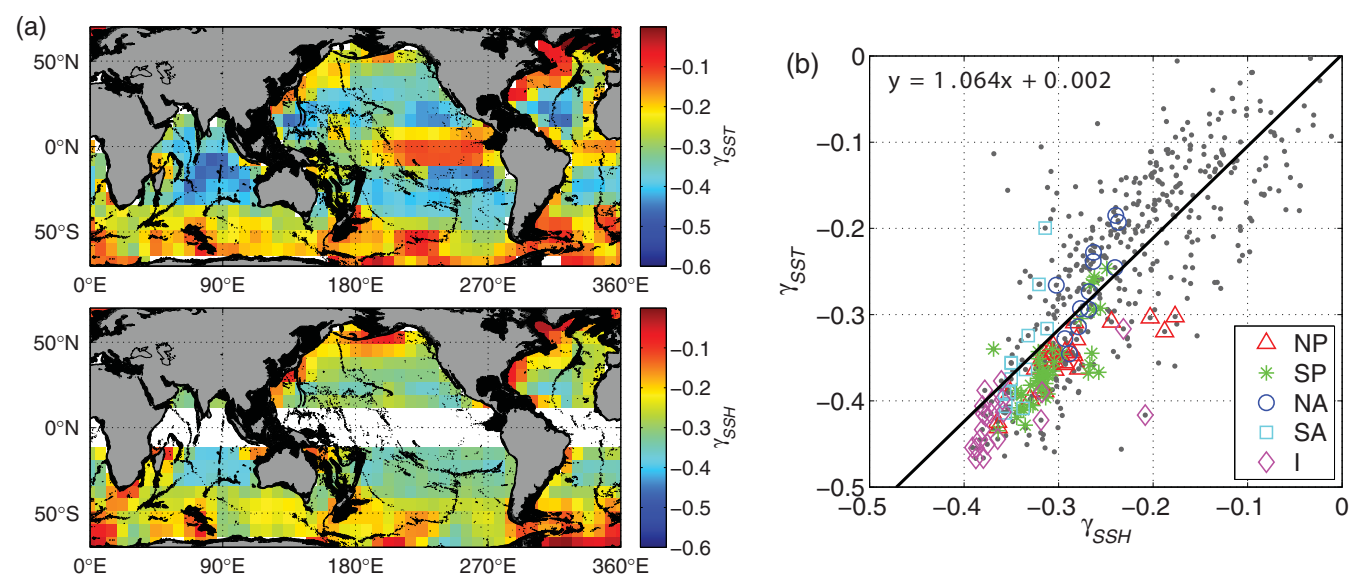

Figure 14. (a) Persistence in meridional SST gradient estimated from AMSR-E SST (June 2002 to May 2011) and mean zonal geostrophic velocity estimated from AVISO ADT (January 1993 to December 2011) as measured by $\gamma$, the decay of standard deviation with averaging period. (b) Plot of $\gamma_{S S T}$ as a function of $\gamma_{S S H}$ with linear fit overlaid. The correlation coefficient is 0.80 , the linear fit has form

$y=1.064 x+0.002$ and the RMS of residuals, $\sqrt{(1 / N) \sum\left(y_{i}-\gamma_{S S T}\right)^{2}}$, is 0.07 . Colored symbols correspond to subtropical regions displayed in Figure 2b. Black contours in Figure 14a denote bathymetric features shallower than $2500 \mathrm{~m}$.

are connected by extremely latent jets. It might be worth noting, here, that we have tried to separate altimeter measurements crossing bands into two groups: those intersecting and not intersecting eddies. In the end, however, even when using along-track altimetry, our attempts were thwarted by the number of mesoscale eddies at these latitudes.

Finally, the meridional shift of SSH with respect to SST (cf. Figures 6 and 9) and the associated shift of the along-band flow with depth (cf. Figure 12d) might carry significance. Indeed, there is some indication that the large-scale flow and the meridional propagation of the bands create the observed meridional tilt (P. Berloff, personal communication, 2014). The significance of this and the above features might be best addressed by applying the SIED/composite averaging techniques to ocean data from a controlled model run (e.g., a model with varying degrees of jet latency such as that of Berloff and Kamenkovich [2013a, $2013 \mathrm{~b}]$ ). Another approach is to apply these methods to infrared SST. Indeed, the tools presented within this study would be useful for identifying where latent jets might exist within the oceans and higherresolution SST may reveal a connected signal between mesoscale eddies.

\subsection{Limitations of the Study}

While we have considerable confidence in the SIED in light of its demonstrated performance when applied to infrared SST [UIIman and Cornillon, 2000], it is nevertheless possible that frontal features have been missed by the algorithm. We acknowledge this possibility. It might be worth noting that the latent jets will be found between neighboring mesoscale eddies. That is, even if the algorithm has missed weak temperature fronts associated with jets, their signatures should reside within the HGEs identified in this study.

A second limitation is the following. Jet-like structures identified in the ocean using the SIED are associated with eastward-flowing geostrophic currents (cf. Figures 6, 9, 11, and 12c, in conjunction with Figure 8). This differs from earlier studies [Maximenko et al., 2005, 2008; Ivanov et al., 2009, 2010; van Sebille et al., 2011; Cravatte et al., 2012; Buckingham and Cornillon, 2013] in which alternating jet-like structures are observed. To understand this perceived discrepancy, we revisit the nature of the detection algorithm [Cayula and Cornillon, 1992] (cf. section 3 and Appendix A). The SIED identifies ocean fronts by searching for more than one temperature population within the histograms of SST measurements. Because the algorithm effectively operates on raw SST measurements, one might say that the algorithm identifies surface fronts in absolute SST. In comparison, the aforementioned studies search for jets within anomaly SST by applying a spatial high pass filter to the data prior to analysis. The end result is that ocean fronts identified by the algorithm follow contours of constant absolute temperature gradient while fronts identified in the aforementioned studies follow contours of gradients in the anomaly fields. This distinction may be important since one approach lends itself to the identification of a staircase-like structure [Dritschel and McIntyre, 2008] within 
SST while the other is more suitable for identifying instabilities within a large-scale temperature gradient. (At present the dynamics of the observed bands and striations are not known to a sufficient degree to merit the choice of one approach over another. Had we spatially high pass filtered microwave SST and averaged for several years, we would have obtained temperature gradients reminiscent of striations in MDT.)

A third and final limitation, we wish to highlight is that the study assumes little seasonal variation of the jets. While we have not overlooked the variation of SST with season in our analysis-we have intentionally minimized its presence within this manuscript in an effort to simplify discussion of the observed zonal bands - using SST for the identification of ocean fronts limits one's analysis to times of the year when temperature gradients permit front identification. In the subtropics, for example, there is generally decreased temperature contrast during summer months and therefore fewer fronts are detected. While we do not expect this is a problem, we mention this in the event that the latent jets are strongest during times when we have difficulty observing SST fronts.

\subsection{Implications for Oceanic Meridional Heat Transport, Air-Sea Interaction, and Primary Productivity}

Before closing, we remark on an observed relationship between SST and SSH in the vicinity of HGEs. In section 4, we noted that in situ temperature anomalies derived from Argo floats display coherent structures to depths greater than $1000 \mathrm{~m}$ but that peak anomalies in surface waters $(0-100 \mathrm{~m})$ were shifted nominally west of those below. This shift or "tilt" of peak temperature anomalies with depth has implications for the meridional flux of heat [Bernstein and White, 1982; Bennett and White, 1986; Roemmich and Gilson, 2001; Qiu and Chen, 2005; Hausmann and Czaja, 2012]. To see this, consider Figures 12a and 12b. While the acrossband component of geostrophic velocity, $v_{b}^{\prime}$, associated with each composite is symmetric about the eddy axis, one observes that temperature anomaly, $T^{\prime}$, is asymmetric about this axis. Here, the eddy axis is most appropriately defined as the location of the extremum in SSH. This results in a nonzero heat flux across the band, $\mathrm{E}\left[v_{b}^{\prime} T^{\prime}\right]$, where $\mathrm{E}[$.] denotes the expectation operator. While we have arrived at this result using composite analyses in a rotated coordinate system-i.e., one that rotates with the local azimuth of the band-a similar analysis using North/East coordinates yields similar offsets [Buckingham, 2013] and would result in estimates of meridional heat flux. Another appropriate coordinate system might be one aligned with the background temperature gradient.

The duration of HGEs might also bear importance. Hovmöller diagrams suggest HGEs (i.e., neighboring cyclonic-anticyclonic anomalies) have durations that last for several months and we have individually tracked these events for periods exceeding 6 months, consistent with neighboring anticyclonic/cyclonic vortices being stable in their position relative to one another. Since mesoscale fronts such as these are known to influence the marine boundary layer [Small et al., 2008; Chelton and Xie, 2010] and enhance primary productivity [Levy, 2008; Klein and Lapeyre, 2009], it is logical to conclude that HGEs and, therefore the bands themselves, are relevant in effecting fluxes between the ocean and atmosphere and biological growth in the oceans.

Finally, a number of studies have recently demonstrated that mesoscale SST is dynamically linked to subsurface density fields and have used this information to estimate interior ocean currents [Lapeyre and Klein, 2006; LaCasce and Mahadevan, 2006; Isern-Fontanet et al., 2006; Wang et al., 2013]. While results within the present study support the underlying assumption of these methods, we emphasize that one must consider the horizontal shift of surface temperatures relative to those below to accurately estimate ocean currents. That is, both SST and SSH (or vertical profiles) should be used to infer subsurface density structure. This may find application, for example, in tropical cyclone prediction where the intensities of such cyclones are determined by their position relative to warm/cool water masses [Emanuel, 1986; Yablonsky and Ginis, 2013].

\section{Appendix A: Overview and Modification of the Ocean Front Detection Algorithm}

During our application of the SIED to microwave measurements of SST, we discovered a sensitivity of the detection algorithm to background temperature gradients, a sensitivity we believe is much more pronounced in AMSR-E than Advanced Very High Resolution Radiometer (AVHRR) data sets. In particular, the existence of background gradients tends to enhance detections. Furthermore, depending on noise characteristics of the underlying data, false detections are possible. Given the topic of this study, the large spatial scale associated with AMSR-E pixels and the existence of a meridional temperature 
(a)

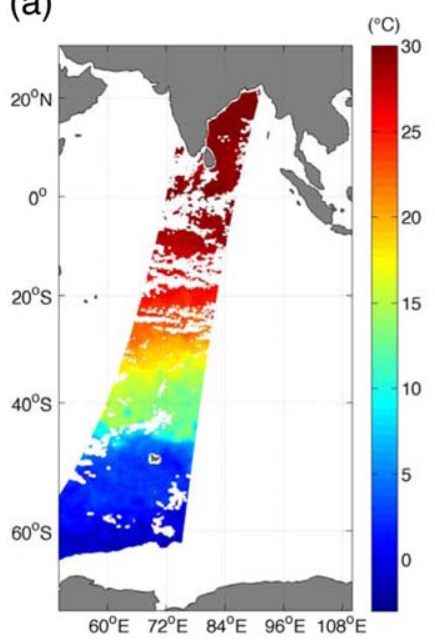

(c)

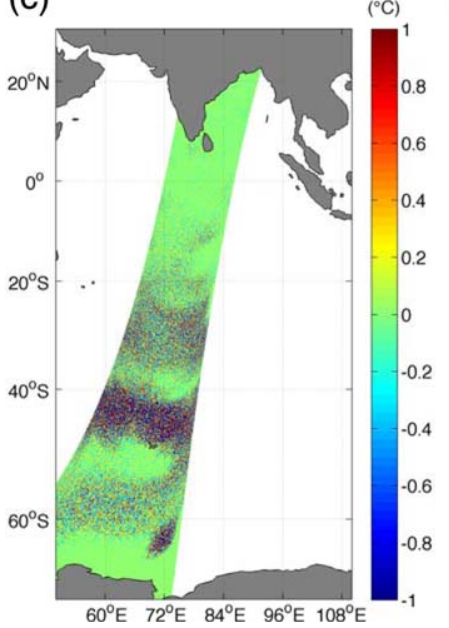

(b)

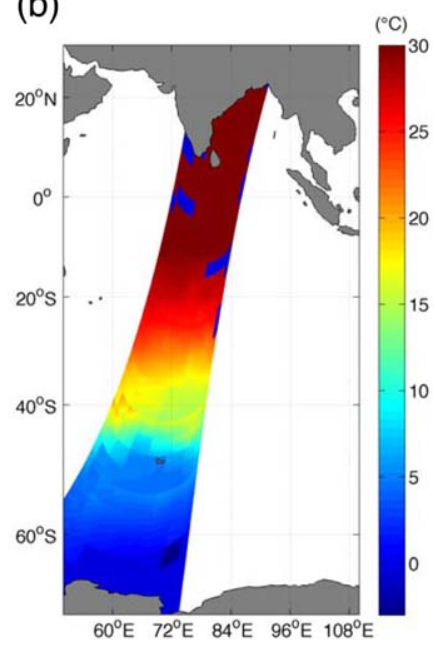

(d)

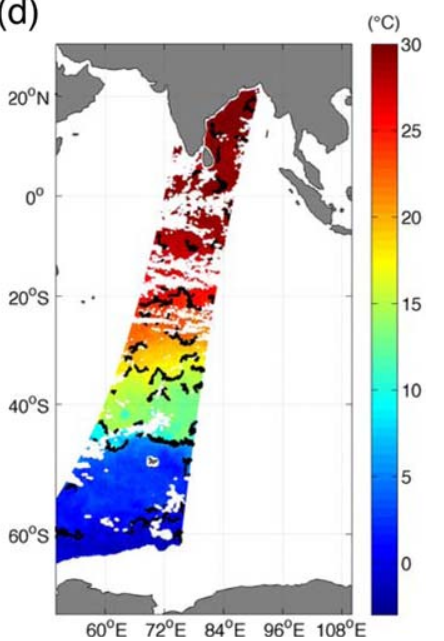

Figure 15. Eliminating the sensitivity of the detection algorithm to background temperature gradients: (a) an example swath image of AMSR-E SST measurements in the Indian Ocean (1 June 2002), (b) illustration of local plane-fits to each tile, (c) WGN with standard deviation determined by the magnitude of background gradients (equation (6)), and (d) front detections overlaid (black) on temperatures depicted in Figure 15a.

gradient between Poles and Equator, we felt it necessary to modify the algorithm to eliminate this sensitivity.

\section{A1. Background}

To understand why background temperature gradients enhance the detection of ocean fronts and, in special cases, result in false front detections, it is necessary to revisit the manner in which the SIED works. As described in section 3.2, the SIED consists of three steps: (1) histogram, (2) cohesion, and (3) contourfollowing steps. In the first step, it computes the histogram of temperatures within overlapping 32-by-32 pixel tiles. If a particular criterion threshold (see below) is exceeded, the tile is flagged as consisting of two temperature populations and the SIED moves to the next step of the algorithm. If the tile is considered cohesive, pixels dividing the two populations are flagged as frontal pixels and the contour-following algorithm connects these pixels.

In assessing whether two populations exist within the histogram of a tile, the SIED searches for a temperature, $\tau=\tau_{\text {opt }}$, which maximizes the following criterion function:

$$
\theta(\tau)=\frac{J_{b}(\tau)}{S_{\text {tot }}}
$$


Here, $J_{b}$ is referred to as the between-cluster variance and $S_{\text {tot }}$ is the total variance within each tile [Cayula and Cornillon, 1992]. The between-cluster variance is given by:

$$
J_{b}(\tau)=\frac{N_{1} N_{2}}{N_{1}+N_{2}}\left[\mu_{1}(\tau)-\mu_{2}(\tau)\right]^{2}
$$

where

$$
N_{1}=\sum_{t<\tau} h(t) \quad \text { and } \quad N_{2}=\sum_{t \geq \tau} h(t)
$$

and the total variance within each tile is:

$$
S_{\text {tot }}=\sum_{t}(t-m)^{2} h(t)
$$

where

$$
m=\frac{\sum_{t} t h(t)}{\sum_{t} h(t)} .
$$

Here, $h(t)$ is the histogram of temperatures, $t$, for each tile and $\tau_{\text {opt }}$ is the temperature separating two populations within a bimodal temperature distribution. Thus, if the ratio of between-cluster variance to total variance exceeds a threshold, $\theta\left(\tau_{\text {opt }}\right)$, the algorithm flags the tile as consisting of two populations.

Cayula [1988] explored several analytical distributions and concluded that a suitable criterion threshold is one near $\theta\left(\tau_{\text {opt }}\right)=0.70$. In the present study, we use a criterion threshold of $\theta\left(\tau_{\text {opt }}\right)=0.72$, with the slightly higher value resulting in a more conservative estimate of front probability. Cayula [1988] also notes that an image tile with uniform histogram has a criterion function whose maximum $(0.75)$ exceeds the threshold and therefore passes the histogram step of the SIED. What is relevant for the present study is that an image with constant temperature gradient has a uniform histogram. Furthermore, such an image is cohesive. Therefore, an image with constant temperature gradient, regardless of the magnitude, can result in front detections. More generally, an increase in the magnitude of the gradient increases the likelihood of front detection.

\section{A2. The Addition of Finite-Amplitude White Noise}

One method of addressing the sensitivity of the detection algorithm to background temperature gradients is to systematically add white Gaussian noise (WGN) to SST tiles prior to computing the histogram. Another method (not explored) is to adaptively vary the criterion threshold depending on the magnitude of the background gradient. The addition of a small amount of normally distributed noise modifies the temperature distribution slightly so as to prevent the tile from passing the histogram test without compromising the performance of the algorithm.

We empirically determined the standard deviation necessary to eliminate false front detections and arrived at the following linear relationship:

$$
\sigma_{N}=(8.14 \text { pixels })\|\nabla T\|
$$

where $\|\nabla T\|$ is the estimated magnitude of the background gradient in units of ${ }^{\circ} \mathrm{C}$ pixel ${ }^{-1}$. Additionally, we estimated the white noise level from wave number spectra of swath SST immediately prior to calculating the histogram in an effort to determine whether data set noise needed to be considered in the overall noise budget. We found the contribution of data set noise to the overall noise budget to be negligible.

\section{A3. Implementation}

We used equation (6) in conjunction with local estimates of background temperature gradients to determine the level of noise necessary to add to AMSR-E SST measurements to eliminate sensitivity to background SST gradients. We illustrate this process for swath measurements in Figure 15. We first estimated the SST gradient magnitude within each tile. This was accomplished by using a singular value decomposition to fit a two-dimensional plane to temperatures within the $64 \times 64$ pixel region centered on each tile. 
We estimated the gradient magnitude as $\|\nabla T\|=\left[(\partial T / \partial x)^{2}+(\partial T / \partial y)^{2}\right]^{1 / 2}$ and used equation (6) to obtain the value of $\sigma_{N}$ for each tile. The plots obtained from the pixels surrounding each tile are illustrated in Figure $15 \mathrm{~b}$. We subsequently interpolated $\sigma_{N}$ values so that corresponding noise magnitudes varied smoothly over the swath pattern (Figure 15c). The histogram test then operated on the modified temperature field, which consisted of the observed SST measurements plus simulated noise. The remainder of the algorithm was not modified. Figure 15d illustrates front detections overlaid on SST measurements.

\section{A4. Comments}

We close this appendix with two comments. First, we have applied this procedure to simulated temperature fronts embedded in a background gradient and concluded that the addition of WGN significantly reduces the likelihood of false front detections. However, this occurs at the expense of the probability of valid front detections. Because of this, estimates of SST front probability presented in the body of this paper are conservative. Second, the SIED's sensitivity to background temperature gradients when applied to infrared SST has not yet been documented. [One method employed in the context of infrared SST was to increase the criterion threshold to 0.76 (D.

\section{Acknowledgments}

We wish to acknowledge the editor, staff, and three anonymous reviewers. We thank D. Chelton and N.

Maximenko for numerous and fruitful discussions over the past several years and C. Gentemann for helpful guidance pertaining to use of microwave SST. O. Melnichenko suggested use of the phrase "eddy train" to describe the organized appearance of eddies and provided details of their filtering process applied to MDT. P. Klein provided a pertinent comment regarding SST, SSH, and meridional heat flux. We also wish to acknowledge the following individuals: P. Berloff, T. Farrar, A. Mahadevan, P. Gaube, A. Czaja, T. Rossby, L. Rothstein, M. Wimbush, R. Watts, D. Ullman, J. Salter, and D. Iwanski. The normalization method was derived from code by E. C. Larsen. Microwave SST measurements were produced and distributed by RSS and sponsored by the NASA Earth Science MEaSUREs DISCOVER Project. The mapped altimeter product was produced by SSALTO/DUACS and distributed by AVISO/CLS with support from CNES Along-track measurements were provided by DEOS and obtained from the Radar Altimeter Database System (RADS) database. Argo profiles were made available by the International Argo Program and the national programs that contribute to it, and were distributed by USGODAE. Climatological profiles from the World Ocean Atlas were obtained from NOAA's National Oceanographic Data Center (NODC). MDOT was distributed and obtained from N. Maximenko and O. Melnichenko (University of Hawaii) and the database of tracked eddies was produced and made available by D. Chelton and M. Schlax (Oregon State University). C.B. was supported by a grant from NASA (NNX10AN69H), P.C. by the State of Rhode Island and Providence Plantations, and F.S. and K.O. by grants from NASA (NNX11AF23G) and NSF (0851794), respectively. Ullman, personal communication, 2010). While this serves to eliminate false detections when the histogram has uniform distribution, it does not eliminate the dependence of the algorithm on background gradients.] The most likely reason for this is that ocean fronts are common in the ocean and background gradients prove helpful in locating these fronts. Another reason may be that geophysical phenomena of small horizontal scale (e.g., aerosol, dust, clouds) act as such a source of noise within the infrared data set. Such signals could thereby modify the temperature distribution and so reduce the sensitivity when using infrared but not microwave measurements.

\section{References}

Afanasyev, Y. D., S. O'Leary, P. B. Rhines, and E. Lindahl (2012), On the origin of jets in the ocean, Geophys. Astrophys. Fluid Dyn., 106(2), $113-137$.

Baldwin, M. P., P. B. Rhines, H.-P. Huang, and M. E. Mclntyre (2007), The jet-stream conundrum, Science, 315, 467-468, doi:10.1126/ science.1131375.

Bennett, A. F., and W. B. White (1986), Eddy heat flux in the subtropical North Pacific, J. Phys. Oceanogr., 16, 728-740.

Berloff, P., and I. Kamenkovich (2013a), On spectral analysis of mesoscale eddies. Part I: Linear analysis, J. Phys. Oceanogr., 43, 2505-2527, doi:10.1175/JPO-D-12-0232.1.

Berloff, P., and I. Kamenkovich (2013b), On spectral analysis of mesoscale eddies. Part II: Nonlinear analysis, J. Phys. Oceanogr., 43, 25282544, doi:10.1175/JPO-D-12-0232.1.

Berloff, P., I. Kamenkovich, and J. Pedlosky (2009), A mechanism of formation of multiple zonal jets in the oceans, J. Fluid Mech., 628, 395425, doi:10.1017/S0022112009006375.

Berloff, P., S. Karabasov, J. T. Farrar, and I. Kamenkovich (2011), On latency of multiple zonal jets in the oceans, J. Fluid Mech., 686, 534-567, doi:10.1017/jfm.2011.345.

Bernstein, R. L., and W. B. White (1982), Meridional eddy heat flux in the Kurioshio Extension Current, J. Phys. Oceanogr., 12, 154-159.

Bostock, H. C., P. J. Sutton, M. J. M. Williams, and B. N. Opdyke (2013), Reviewing the circulation and mixing of Antarctic Intermediate Water in the South Pacific using evidence from geochemical tracers and Argo float trajectories and the associated heat transport, Deep Sea Res., Part l, 73, 84-98, doi:10.1016/j.dsr.2012.11.007.

Buckingham, C. E. (2013), Ubiquitous zonal bands in subtropical oceans observed from space, PhD thesis, Grad. Sch. of Oceanogr., Univ. of Rhode Island, Kingston.

Buckingham, C. E., and P. C. Cornillon (2010), Observed quasi-zonal banded structures in SST frontal probability: Why do we see them?, paper presented at AGU/TOS/ASLO Ocean Sciences 2010 Conference, Portland, Oreg.

Buckingham, C. E., and P. C. Cornillon (2013), The contribution of eddies to striations in absolute dynamic topography, J. Geophys. Res., 118, 448-461, doi:10.1029/2012JC008231.

Cayula, J.-F. (1988), Edge detection algorithm for SST images, MSc thesis, Electr. Eng., Univ. of Rhode Island, Kingston.

Cayula, J.-F., and P. C. Cornillon (1992), Edge detection algorithm for SST images, J. Atmos. Oceanic Technol., 9, 67-80.

Centurioni, L., J. Ohlmann, and P. Niiler (2008), Permanent meanders in the California Current System, J. Phys. Oceanogr., 38, 1690-1710, doi:10.1175/2008JPO3746.1.

Chaigneau, A., M. Le Texier, G. Eldin, C. Grados, and O. Pizarro (2011), Vertical structure of mesoscale eddies in the eastern South Pacific Ocean: A composite analysis from altimetry and Argo profiling floats, J. Geophys. Res., 116, C11025, doi:10.1029/2011JC007134.

Charney, J. G. (1971), Geostrophic turbulence, J. Atmos. Sci., 28, 1087-1095.

Chelton, D. B., and F. J. Wentz (2005), Global microwave satellite observations of sea surface temperature for numerical weather prediction and climate research, Bull. Am. Meteorol. Soc., 86, 1097-1115, doi:10.1175/BAMS-86-8-1097.

Chelton, D. B., and S.-P. Xie (2010), Coupled ocean-atmosphere interaction at oceanic mesoscales, Oceanography, 23(4), 52-69, doi: 10.5670/oceanog.2010.05.

Chelton, D. B., J. C. Ries, B. J. Haines, L.-L. Fu, and P. S. Callahan (2001), Satellite altimetry, in Satellite Altimetry and Earth Sciences: A Handbook of Techniques and Applications, edited by L.-L. Fu and A. Cazenave, pp. 1-131, Academic, San Diego, Calif.

Chelton, D. B., M. G. Schlax, and R. M. Samelson (2011a), Global observations of nonlinear mesoscale eddies, Prog. Oceanogr., 91, 167-216, doi:10.1016/j.pocean.2011.01.002.

Chelton, D. B., P. Gaube, M. G. Schlax, J. J. Early, and R. M. Samelson (2011b), The influence of nonlinear mesoscale eddies on near-surface oceanic chlorophyll, Science, 334(6054), 328-332.

Cheney, R., L. Miller, R. Agreen, N. Doyle, and J. Lillibridge (1994), TOPEX/POSEIDON: The 2-cm solution, J. Geophys. Res., 99, 24,555-24,563, doi:10.1029/94JC02050. 
Cravatte, S., W. Kessler, and F. Marin (2012), Intermediate zonal jets in the tropical Pacific Ocean observed by Argo floats, J. Phys. Oceanogr., 42, 1475-1485, doi:10.1175/JPO-D-11-0206.1.

Cushman-Roisin, B., E. P. Chassignet, and B. Tang (1990), Westward motion of mesoscale eddies, J. Phys. Oceanogr., 20, 758-768.

Daszykowski, M., B. Walczak, and D. L. Massart (2001), Looking for natural patterns in data. Part 1: Density based approach, Chemometrics Intel. Lab. Syst., 56(2001), 83-92.

Deans, S. R. (1993), The Radon Transform and Some of its Applications, 2nd ed., Krieger, Malabar, Fla.

Di Lorenzo, E., A. Belmadani, H. Luo, O. Melnichenko, N. Schneider, and N. Maximenko (2012), The emergence of striations in the North Pacific circulation, paper presented at AGU/TOS/ASLO Ocean Sciences 2012 Conference, Salt Lake City, Utah.

Divakaran, P., and G. B. Brassington (2011), Arterial ocean circulation of the southeast Indian Ocean, Geophys. Res. Lett., 38, L01802, doi: 10.1029/2010GL045574.

Dong, S., J. Sprintall, and S. T. Gille (2006), Location of the Antarctic polar front from AMSR-E satellite sea surface temperature measurements, J. Phys. Oceanogr., 36, 2075-2089, doi:10.1175/JPO2973.1.

Dritschel, D. G., and M. E. Mclntyre (2008), Multiple jets as PV staircases: The Phillips effect and the resilience of eddy-transport barriers, J. Atmos. Sci., 65, 855-874, doi:10.1175/2007JAS2227.1.

Ducet, N., P. Y. LeTraon, and G. Reverdin (2000), Global high-resolution mapping of ocean circulation from TOPEX/Poseidon and ERS-1 and -2, J. Geophys. Res., 105, 477-498.

Emanuel, K. A. (1986), An air-sea interaction theory for tropical cyclones. Part I: Steady state maintenance, J. Atmos. Sci., 43, 585-604.

Ester, M., H.-P. Kriegel, J. Sander, and X. Xu (1996), A density-based algorithm for discovering clusters in large spatial databases with noise, in Proceedings of 2nd International Conference on Knowledge Discovery and Data Mining, edited by E. Simoudis, J. Han, and U. Fayyad, pp. 226-231, AAAI Press, Menlo Park, Calif.

Galperin, B., H. Nakano, H.-P. Huang, and S. Sukoriansky (2004), The ubiquitous zonal jets in the atmospheres of giant planets and Earth's oceans, Geophys. Res. Lett., 13, L13303, doi:10.1029/2004GL019691.

Harris, F. J. (1978), On the use of windows for harmonic analysis with the discrete Fourier transform, Proc. IEEE, 66, 51-84.

Hausmann, U., and A. Czaja (2012), The observed signature of mesoscale eddies in sea surface temperature and the associated heat transport, Deep Sea Res., Part I, 70, 60-72, doi:10.1016/j.dsr.2012.08.005.

Hogg, N. G., and W. B. Owens (1999), Direct measurement of the deep circulation within the Brazil Basin, Deep Sea Res., Part II, 46, $335-353$.

Hristova, H. G., J. Pedlosky, and M. A. Spall (2008), Radiating instability of a meridional boundary current, J. Phys. Oceanogr., 38, 2294-2307, doi:10.1175/2008JPO3853.1.

Huang, H.-P., A. Kaplan, E. N. Curchitser, and N. A. Maximenko (2007), The degree of anisotropy for mid-ocean currents from satellite observations and an eddy-permitting model simulation, J. Geophys. Res., 36, C09005, doi:10.1029/2007JC004105.

Isern-Fontanet, J., B. Chapron, G. Lapeyre, and P. Klein (2006), Potential use of microwave sea surface temperatures for the estimation of ocean currents, Geophys. Res. Lett., 33, L24608, doi:10.1029/2006GL027801.

Ivanov, L. M., C. A. Collins, and T. M. Margolina (2009), System of quasi-zonal jets off California revealed from satellite altimetry, Geophys. Res. Lett., 36, L03609, doi:10.1029/2008GL036327.

Ivanov, L. M., C. A. Collins, T. M. Margolina, and V. N. Eremeev (2010), Nonlinear Rossby waves off California, Geophys. Res. Lett., 37, L13602, doi:10.1029/2010GL043708.

Kamenkovich, I., P. Berloff, and J. Pedlosky (2009), Role of eddy forcing in the dynamics of multiple zonal jets in a model of the North Pacific, J. Phys. Oceanogr., 39, 1361-1379, doi:10.1175/2008JPO4096.1.

Katsaros, K. (1980), The aqueous thermal boundary layer, Boundary Layer Meteorol., 18, 107-127.

Klein, P., and G. Lapeyre (2009), The oceanic vertical pump induced by mesoscale and submesoscale turbulence, Annu. Rev. Mar. Sci., 1 , 351-375, doi:10.1146/annurev.marine.010908.163704.

LaCasce, J. H., and A. Mahadevan (2006), Estimating subsurface horizontal and vertical velocities from sea-surface temperature, J. Mar. Res., $64,695-721$.

Lapeyre, G. (2009), What vertical mode does the altimeter reflect? On the decomposition in baroclinic modes and on a surface-trapped mode, J. Phys. Oceanogr., 39, 2857-2874.

Lapeyre, G., and P. Klein (2006), Dynamic of the upper oceanic layers in terms of surface quasi-geostrophy theory, J. Phys. Oceanogr., 36, $165-176$.

Le Traon, P. Y., Y. Faugère, F. Hernandez, F. M. J. Dorandeu, and M. Ablain (2003), Can we merge GEOSAT follow-on with TOPEX/Poseidon and ERS-2 for an improved description of the ocean circulation?, J. Atmos. Oceanic Technol., 20, 889-895.

Levy, M. (2008), The modulation of biological production by oceanic mesoscale turbulence, in Transport in Geophysical Flow: Ten Years After, Lecture Notes in Physics, vol. 744, edited by J. B. Weiss and A. Provenzale, pp. 219-261, Springer, Berlin.

Martin, S. (2004), An Introduction to Ocean Remote Sensing, 426 pp., Cambridge Univ. Press, Cambridge, U. K.

Marshall, D., B. Vogel, and X. Zhai (2013), Rossby rip currents, Geophys. Res. Lett., 40, 4333-4337, doi:10.1002/grl.50842.

Maximenko, N., B. Bang, and H. Sasaki (2005), Observational evidence of alternating zonal jets in the World Ocean, Geophys. Res. Lett., 32, L12607, doi:10.1029/2005GL022728.

Maximenko, N., O. V. Melnichenko, P. P. Niiler, and H. Sasaki (2008), Stationary mesoscale jet-like features in the ocean, Geophys. Res. Lett., 35, L08603, doi:10.1029/2008GL033267.

Maximenko, N., P. Niiler, L. Centurioni, M.-H. Rio, O. Melnichenko, D. Chambers, V. Zlotnicki, and B. Galperin (2009), Mean dynamic topography of the ocean derived from satellite and drifting buoy data using three different techniques, J. Atmos. Oceanic Technol., 26, 19101919, doi:10.1175/2009JTECHO672.1.

Melnichenko, O. V., N. A. Maximenko, N. Schneider, and H. Sasaki (2010), Quasi-stationary striations in basin-scale oceanic circulation: Vorticity balance from observations and eddy-resolving model, Ocean Dyn., 60, 653-666.

O'Reilly, C. H., A. Czaja, and J. H. LaCasce (2012), The emergence of zonal ocean jets under large-scale stochastic wind forcing, Geophys. Res. Lett., 39, L11606, doi:10.1029/2012GL051684.

Park, J. J., and K. Kim (2013), Deep currents obtained from Argo float trajectories in the Japan/East Sea, Deep Sea Res., Part II, 85, 169-181, doi:10.1016/j.dsr2.2012.07.032.

Pedlosky, J. (1975), On secondary baroclinic instability and the meridional scale of motion in the ocean, J. Phys. Oceanogr., 5, $603-607$.

Qiu, B., and S. Chen (2005), Eddy-induced heat transport in the subtropical North Pacific from Argo, TMl, and altimetry measurements, J. Phys. Oceanogr., 35, 458-473.

Qiu, B., D. L. Rudnick, S. Chen, and Y. Kashino (2013), Quasi-stationary North Equatorial Undercurrent jets across the tropical North Pacific Ocean, Geophys. Res. Lett., 40, 2183-2187, doi:10.1002/grl.50394.

Rhines, P. B. (1975), Waves and turbulence on a beta-plane, J. Fluid Mech., 69, 417-443. 
Rhines, P. B. (1994), Jets, Chaos, 4, 313-339.

Rio, M. H., S. Guinehut, and G. Larnicol (2011), New CNES-CLS09 global mean dynamic topography computed from the combination of GRACE data, altimetry, and in situ measurements, J. Geophys. Res., 116, C07018, doi:10.1029/2010JC006505.

Robinson, A. R., (Ed.) (1983), Eddies in Marine Science, 609 pp., Springer, N. Y.

Roemmich, D., and J. Gilson (2001), Eddy transport of heat and thermocline waters in the North Pacific: A key to interannual/decadal climate variability?, J. Phys. Oceanogr., 31, 675-687.

Roemmich, D., et al. (2001), Argo: The global array of profiling floats, in Observing the Oceans in the 21st Century, edited by C. J. Koblinsky and N. R. Smith, pp. 248-258, GODAE Proj. Off. and Bur. of Meteorol., Melbourne, Victoria, Australia.

Schlax, M. G., and D. B. Chelton (2008), The influence of mesoscale eddies on the detection of quasi-zonal jets in the ocean, Geophys. Res. Lett., 35, L24602, doi:10.1029/2008GL035998.

Scott, R. B., B. K. Arbic, C. L. Holland, A. Sen, and B. Qiu (2008), Zonal versus meridional velocity variance in satellite observations and realistic and idealized ocean circulation models, Ocean Modell., 23, 102-112, doi:10.1016/j.ocemod.2008.04.009.

Small, R. J., S. P. de Szoeke, S. P. Xie, L. O'Neill, H. Seo, Q. Song, P. Cornillon, M. Spall, and S. Minobe (2008), Air-sea interaction over fronts and eddies, Dyn. Atmos. Oceans, 45, 274-319, doi:10.1016/j.dynatmoce.2008.01.001.

Sokolov, S., and S. R. Rintoul (2007), Multiple jets of the Antarctic Circumpolar Current south of Australia, J. Phys. Oceanogr., 37, 1394-1412, doi:10.1175/JPO3111.1.

Ullman, D. S., and P. C. Cornillon (2000), Evaluation of front detection methods for satellite-derived SST data using in situ observations, J. Atmos. Oceanic Technol., 17, 1667-1675.

van Sebille, E., I. Kamenkovich, and J. K. Willis (2011), Quasi-zonal jets in 3D Argo data of the northeast Atlantic, Geophys. Res. Lett., 38, L02606, doi:10.1029/2010GL046267.

Wang, J., M. A. Spall, G. R. Flierl, and P. Malanotte-Rizzoli (2012), A new mechanism for the generation of quasi-zonal jets in the ocean, Geophys. Res. Lett., 39, L10601, doi:10.1029/2012GL051861.

Wang, J., G. R. Flierl, J. H. LaCasce, J. L. McClean, and A. Mahadevan (2013), Reconstructing the ocean's interior from surface data, J. Phys. Oceanogr., 43, 1611-1626, doi:10.1175/JPO-D-12-0204.1.

Wunsch, C. (1997), The vertical partition of oceanic horizontal kinetic energy, J. Phys. Oceangr., 27, 1770-1794.

Wunsch, C., and D. Stammer (1998), Satellite altimetry, the marine geoid, and the ocean general circulation, Annu. Rev. Earth Planet. Sci., 26, 219-253.

Wyrtki, K., L. Magaard, and J. Hagerand (2013), Eddy energy in the oceans, J. Geophys. Res., 81, 2641-2646.

Yablonsky, R., and I. Ginis (2013), Impact of a warm ocean eddy's circulation on hurricane-induced sea surface cooling with implications for hurricane intensity, Mon. Weather Rev., 141, 997-1021, doi:10.1175/MWR-D-12-00248.1. 